\title{
Review Article \\ Protonation Equilibria of Biologically Active Ligands in Mixed Aqueous Organic Solvents
}

\author{
Ahmed A. El-Sherif, ${ }^{1,2}$ Mohamed M. Shoukry, ${ }^{1,3}$ \\ Abeer T. Abd Elkarim, ${ }^{1}$ and Mohammad H. Barakat ${ }^{4}$ \\ ${ }^{1}$ Chemistry Department, Faculty of Science, Cairo University, Giza, Egypt \\ ${ }^{2}$ Department of Chemistry, Faculty of Arts and Science, Northern Border University, Rafha, Saudi Arabia \\ ${ }^{3}$ Department of Chemistry, Faculty of Science, Islamic University, Al-Madinah, Saudi Arabia \\ ${ }^{4}$ Holding Company for Water and Waste Water, The Reference Laboratory for Drinking Water, Inorganic Laboratory, Cairo, Egypt
}

Correspondence should be addressed to Ahmed A. El-Sherif; aelsherif72@yahoo.com

Received 11 May 2014; Accepted 16 July 2014; Published 14 August 2014

Academic Editor: Spyros P. Perlepes

Copyright (C) 2014 Ahmed A. El-Sherif et al. This is an open access article distributed under the Creative Commons Attribution License, which permits unrestricted use, distribution, and reproduction in any medium, provided the original work is properly cited.

\begin{abstract}
The review is mainly concerned with the protonation equilibria of biologically active ligands like amino acids, peptides, DNA constituents, and amino acid esters in nonaqueous media. Equilibrium concentrations of proton-ligand formation as a function of $\mathrm{pH}$ were investigated. Also, thermodynamics associated with protonation equilibria were also discussed.
\end{abstract}

\section{Introduction}

There is a growing interest in studying the properties of biologically active ligands like amino acids, peptides, DNA, and amino acid esters. Amino acids and peptides have special importance among the other chemical groups since they are the foundation stones of the living organisms. They are not only components of tissues, but also reactive organic compounds which are important regulators of biological processes. It is obvious that one has to know the physical properties of amino acids and peptides in order to explain the behavior and synthesis of proteins and enzymes in the organisms. The study of amino acids, peptides, or DNA units has been the subject of increasing research efforts, which have revealed the role of hydrogen ion at molecular level. These compounds are usually considered as good model systems to attain a better insight into the characteristics of naturally occurring copper metalloproteins [1]. The data related to the protonation constants of biologically active ligands in various media will be valuable in further understanding of their chemistry in biological systems. Also, analytical chemists are supposed to know the related constants of the species present in the medium to determine the accuracy and most suitable medium for their analysis.
The major reasons for the determination of protonation constants can be summarized as follows: one can calculate the $\mathrm{pH}$ and the ratio of different forms of a certain substance by the use of its protonation constants. Due to the fact that different forms of different substances have different UV spectra, by choosing a suitable $\mathrm{pH}$ value one can carry out spectrophotometric quantitative analyses. The choice of the $\mathrm{pH}$ value requires knowledge of protonation constants. Protonation constants are important in preparative chemistry as well. If the protonation constants of a certain substance are known, it is possible to isolate it with a maximum yield by finding the $\mathrm{pH}$ range where the compounds show minimum ionization. Protonation of a newly synthesized compound can also give supportive information about its structure. If theoretically calculated protonation constants are in good accordance with the experimental values, it is possible that the proposed structure could be correct. It is necessary that the protonation constants be known in order to prepare buffer solutions at different $\mathrm{pH}$ values [2]. There are various techniques such as conductometry, spectrophotometry, and potentiometry [3-5] that are used in the determination of protonation constants. In addition, for the calculations of stability constants of the complex formation of biologically active ligands with metal ions, their protonation constants 
are used [6]. Knowledge of the equilibrium constants of some compounds is necessary for the calculation of the concentration of each ionized species at any $\mathrm{pH}$, which is important for the complete understanding of the physicochemical behavior of such molecules [6].

Mostly, physical constants of bioligands are studied in aqueous media. Despite this, little is known about the chemistry of biomolecules in the mixtures of organic solvents and water, in regard to either protonation constants or synthetic applications. One reason for this dearth of knowledge is that in vivo reactions take place in aqueous media, so that interest in bioligands properties in aqueous solution has predominated. However, in the literature it has been shown that water is not an ideal model for in vivo reactions. In enzymes, membranes, and other biologically important media, the $\mathrm{p} K_{\mathrm{a}}$ values are far different from those in water, as these media tend to be lipophilic rather than hydrophilic $[7,8]$. Studies in media other than water should provide some understanding of the chemistry of bioligands in living systems. With this in mind and in continuation of our research program directed to study the solution equilibria of biologically active compounds [9-15], the present review discusses the valuable information existing in the literature for some bioactive ligands like amino acids, amino acid esters, peptides, and DNA constituents in nonaqueous media.

\section{Determination of Protonation Constants of Biologically Active Ligands}

The determination of equilibrium constants is an important process for many branches of chemistry [16]. Developments in the field of computation of equilibrium constants from experimental data were reviewed by Legget [17] and Meloum et al. [18]. Since that time, many more programs have been published, mainly so as to be able to use microcomputers for the computations. The most commonly used programs for solution equilibrium constant determination are PKPOT [19], PKAS [20], BEST [21], MINIQUAD [22], MINIQUAD75 [23], SUPERQUAD [24], PSEQUAD [25], and HYPERQUAD [26]. All of these programs use least-square refinements to reduce the differences between calculated and experimental data to get the best model that gives the best fit. The sum of square of residuals between experimental and calculated values is normally very small; it is typically between $10^{-6}$ and $10^{-9}$.

\section{Protonation Equilibria in Nonaqueous Solutions}

Vast data are available on the protonation and stability constants of the bioligands in aqueous solutions [27-40]. But the knowledge which may be obtained from mixed solvents could complement the vast amount of data collected from studies on the chemistry of bioligands in aqueous media. Water-organic solvent mixtures have attracted much interest because of their frequent use and wide field of applications. These solvent mixtures are also used as reaction media for a variety of organic and analytical processes such as synthesis, titrations, or liquid chromatographic separations.
Solvent molecules act as proton acceptors and therefore the solvent plays a crucial role in chemical and biochemical reactions. The acid-base behavior of substances in these mixtures is of considerable interest and importance. Data related to protonation constants will be valuable in the further understanding of biological systems. Hence, studies in media other than water should provide some understanding of the chemistry of bioligands in living systems.

3.1. Autoprotolysis Constants $\left(K_{a p}\right)$. The autoprotolysis constant $\left(K_{\mathrm{ap}}\right)$ of a solvent is an important parameter in understanding acid-base equilibria in mixed solvents. It also determines the extreme limits of acidity and basicity in a given solvent medium. The dielectric constant and the intrinsic acidic and basic strength of the solvent will influence the self-ionization process in these media. The recent IUPAC document on the criteria for standardization of $\mathrm{pH}$ measurements in organic solvent and water-organic solvent mixtures underlines the importance of knowing the autoprotolysis constant (in fact, $-\log _{10} K_{\mathrm{ap}}=$ normal scale length of $\mathrm{pH}$ ) pertaining to each solvent considered, which can be achieved by appropriate thermodynamic methods [41]. Various methods have been used to obtain values of the autoprotolysis constants in aqueous organic solvent mixtures by potentiometry [42]. These experimental methods are difficult, and those methods that make use of the hydrogen electrode can only be applied to systems in which there is no complication due to reduction at the hydrogen electrode. Furthermore, Rosés et al. $[43,44]$ derived equations to calculate autoprotolysis constants of aqueous organic solvent mixtures and they expressed that all of the autoprotolysis processes are determined by the polarity and hydrogen bounding capability of solvents. Kiliç and Aslan [45] derived a convenient and rapid potentiometric technique using a combined glass-pH electrode for the determination of autoprotolysis constants in a variety of aqueous organic mixed solvents. For different compositions of organic solvent-water mixtures, reproducible values of autoprotolysis constants were calculated from several separate series of $\left[\mathrm{H}^{+}\right]$ and $\left[\mathrm{OH}^{-}\right]$measurements as given in Tables 1 and 2 [45-51].

\subsection{Protonation Equilibria in Mixed Ethanol-Water Medium.} Among the organic solvents, ethanol is closest to water in structure and properties and therefore the behaviour of dissociation or protonation in ethanol is similar to that of aqueous solution. The water-ethanol mixture is a very interesting binary mixture. One reason is that ethanol can dissolve a majority of organic acids and bases more effectively than water. However, it has been suggested that solvents such as water-ethanol mixtures provide a better model for in vivo reactions $[52,53]$ because the mixtures simultaneously show a low polar character and partially aqueous contents, as do all biological systems. In addition, ethanol-water mixtures are a suitable solvent for the determination of equilibrium constants [53-56]. In addition, there has been increasing interest during the past few years in the properties of mixed-solvent systems such as polar aprotic solvents and water. Water and organic solvents such as methanol, ethanol, acetone, and acetonitrile are completely miscible. Their mixtures are macroscopically homogeneous, but it has 
TABLE 1: The autoprotolysis constants $\left(K_{\mathrm{ap}}\right)$ obtained for various water-solvent mixtures.

\begin{tabular}{lc}
\hline Medium & $\mathrm{p} K_{\text {ap }}$ \\
\hline Water & $13.78^{\mathrm{a}}, 13.69^{\mathrm{b}}, 13.77^{\mathrm{c}}$ \\
20\% ethanol-80\% water & $14.03^{\mathrm{d}}$ \\
$30 \%$ ethanol-70\% water & $14.17^{\mathrm{a}}, 14.16^{\mathrm{b}}$ \\
$40 \%$ ethanol-60\% water & $14.30^{\mathrm{d}}$ \\
$50 \%$ ethanol-50\% water & $14.40^{\mathrm{a}}, 14.28^{\mathrm{b}}$ \\
$60 \%$ ethanol-40\% water & $14.48^{\mathrm{d}}$ \\
$70 \%$ ethanol-30\% water & $14.67^{\mathrm{a}}, 14.59^{\mathrm{b}}$ \\
12.5\% dioxane-87.5\% water & $14.17^{\mathrm{e}}$ \\
20\% dioxane-80\% water & $14.31^{\mathrm{f}}, 14.22^{\mathrm{b}}$ \\
25\% dioxane-75\% water & $14.37^{\mathrm{e}}$ \\
37.5\% dioxane-62.5\% water & 14.50 \\
$40 \%$ dioxane-60\% water & $14.89^{\mathrm{f}}, 14.86^{\mathrm{b}}$ \\
$50 \%$ dioxane-50\% water & $15.44^{\mathrm{e}}$ \\
60\% dioxane-40\% water & $15.54^{\mathrm{f}}, 15.62^{\mathrm{b}}$ \\
$62.5 \%$ dioxane-37.5\% water & $15.70^{\mathrm{e}}$ \\
$70 \%$ dioxane-30\% water & $15.75^{\mathrm{e}}$ \\
$50 \%$ DMSO-50\% water & $15.48^{\mathrm{g}}$ \\
\hline
\end{tabular}

${ }^{\mathrm{a}}$ Data taken from reference [38], b data taken from reference [37], ${ }^{\mathrm{c}}$ data taken from reference [39], data taken from reference [40], e data taken from reference [41], ${ }^{f}$ data taken from reference [42], and ${ }^{g}$ data taken from reference [43].

been reported that the water and organic solvent molecules are not homogeneously dispersed microscopically, because of the hydrogen-bonding network formation and hydrophobic interactions [46]. Consequently, the molecular composition of the solvation layer around a solute molecule is not the same as that of the bulk mixing ratio of water and organic solvent. The hydrophobic and hydrophilic properties of a solute may be reflected by preferential solvation in such mixed solvents. Therefore, the influence which the solvent exerts on the $\log _{10} K$ values depends upon the extent and nature of the solute-solvent interaction, which involves species participating in the acid-base equilibrium. Also, analytical chemists are supposed to know the related constants of the species present in the medium to determine the accuracy and most suitable medium for their analysis. Protonation constants of some $\alpha$ amino acids at different water-ethanol mixtures are given in Tables 3-7 [45, 55, 57-63].

\subsubsection{Protonation Equilibria of Amino Acids in Mixed Water-Ethanol Medium}

(1) Protonation Equilibria of L-Cysteine and L-Tyrosine in Mixed Water-Ethanol Medium (Figure 1). The protonation constants of L-cysteine and L-tyrosine given in Table 3 correspond to the following equilibria:

$$
\begin{array}{cc}
\mathrm{L}^{2-}+\mathrm{H}^{+} \rightleftharpoons \mathrm{HL}^{-} & K_{1}=\frac{\left[\mathrm{HL}^{-}\right]}{\left[\mathrm{L}^{2-}\right]\left[\mathrm{H}^{+}\right]} \\
\mathrm{HL}^{-}+\mathrm{H}^{+} \rightleftharpoons \mathrm{H}_{2} \mathrm{~L} & K_{2}=\frac{\left[\mathrm{H}_{2} \mathrm{~L}\right]}{\left[\mathrm{HL}^{-}\right]\left[\mathrm{H}^{+}\right]} \\
\mathrm{H}_{2} \mathrm{~L}+\mathrm{H}^{+} \rightleftharpoons \mathrm{H}_{3} \mathrm{~L}^{+} & K_{3}=\frac{\left[\mathrm{H}_{3} \mathrm{~L}^{+}\right]}{\left[\mathrm{H}_{2} \mathrm{~L}\right]\left[\mathrm{H}^{+}\right]}
\end{array}
$$<smiles>NC(Cc1ccc(O)cc1)C(=O)O</smiles>

Tyrosine (Tyr)

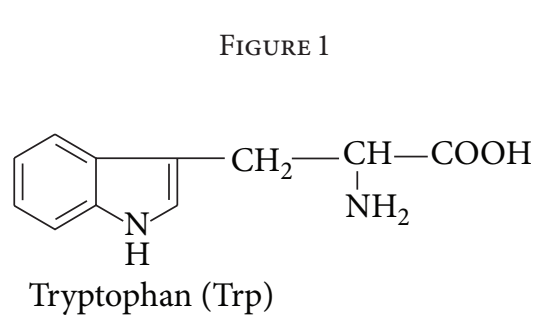

\section{$\mathrm{H}_{2} \mathrm{C}-\mathrm{C}-\mathrm{C}-\mathrm{COOH}$
SH $\mathrm{NH}_{2}$}

Cysteine (Cys)
FIGURE 1

FiguRE 2

FIGUR 2
The $\log _{10} K_{1}$ values are related to the attachment of $\mathrm{H}^{+}$ to the phenolic oxygen in L-tyrosine and attachment of $\mathrm{H}^{+}$to the $-\mathrm{NH}_{2}$ group in L-cysteine. The $\log _{10} K_{2}$ value corresponds to the attachment of a proton to the $-\mathrm{NH}_{2}$ and sulfur thiol groups in L-tyrosine and L-cysteine, respectively. The $\log _{10} K_{3}$ values are the smallest and are thought to correspond to the protonation of carboxyl groups. The decrease in the $\log _{10} K_{2}$ value with increasing ethanol concentration can be explained by the fact that the dipolar ionic form is more strongly solvated than the anionic form in aqueous media.

(2) Protonation Equilibria of L-Tryptophane in Mixed WaterEthanol Medium (Figure 2). Two protonation equilibria were found for L-tryptophan. The first protonation constant was attributed to the protonation of $-\mathrm{NH}_{2}$ and the second one was related to protonation of carboxyl group. No protonation constants were found related to the protonation of the nitrogen atom of the indole ring of this amino acid. The decrease in $\log _{10} K_{1}$ values of L-tryptophane was observed with the increase of ethanol concentration. This can be explained by better solvation of the dipolar ionic form.

(3) Protonation Equilibria of L-Lysine and Histidine in Mixed Water-Ethanol Medium (Figure 3). L-lysine contains $-\mathrm{NH}_{2}$ group in the side chain. Due to the fact that this amino group is far from the carboxyl groups, resulting in a lesser degree of inductive effect, it can be said that $\log _{10} K_{1}$ is related to the protonation of this amino group. The second and third protonation equilibria belong to the $\alpha$-amino and carboxyl groups, respectively. For L-histidine, the $\log _{10} K_{1}$ and $\log _{10} K_{2}$ values are related to the protonation of $-\mathrm{NH}_{2}$ and the nitrogen in imidazole groups, respectively. The third constant $\left(\log _{10} K_{3}\right)$ belongs to the protonation of the carboxylate group.

The $\log _{10} K_{1}$ and $\log _{10} K_{2}$ values of L-lysine decrease with increasing ethanol concentration in the solvent mixture. Although, in the first equilibrium involving $K_{1}$, HL seems to be an uncharged species, it belongs to the dipolar form of amino acid. If we consider the solvation of these species, the fact that both $K_{1}$ and $K_{2}$ decrease with increasing ethanol concentration seems highly reasonable. The fact that the $\log _{10} K_{1}$ value of L-histidine decreases with increasing ethanol concentration can be explained by the fact that dipolar HL 
TABLE 2: The autoprotolysis constants $\left(K_{\mathrm{ap}}\right)$ obtained for various water-organic solvent mixtures measured in an ionic medium of $0.1 \mathrm{~mol} \cdot \mathrm{dm}^{-3} \mathrm{NaClO}_{4}$ at $25^{\circ} \mathrm{C}^{\mathrm{a}}$.

\begin{tabular}{lccccccccc}
\hline \multirow{2}{*}{ Organic component } & \multicolumn{9}{c}{ Organic component \% } \\
& 0 & 10 & 20 & 30 & 40 & 50 & 60 & 70 & 80 \\
\hline Methanol & 13.69 & 13.75 & 13.78 & 13.70 & 13.73 & 13.71 & 13.72 & 13.77 & 13.94 \\
Ethanol & 13.69 & 13.82 & 13.99 & 14.16 & 14.24 & 14.28 & 14.39 & 14.59 & 14.77 \\
1-Propanol & 13.69 & 13.78 & 13.98 & 14.04 & 14.15 & 14.31 & 14.46 & 14.61 & 14.82 \\
2-Propanol & 13.69 & 13.76 & 13.95 & 14.05 & 14.26 & 14.34 & 14.56 & 14.79 & - \\
Dioxane & 13.69 & 13.91 & 14.22 & 14.51 & 14.86 & 15.24 & 15.62 & - & - \\
Acetonitrile & 13.69 & 13.96 & 14.19 & 14.44 & 14.74 & 15.04 & - & - \\
\hline
\end{tabular}

${ }^{a}$ Data taken from reference [37].

The $\%$ is expressed as (volume/Volume).

TABle 3: Protonation constants of some $\alpha$-amino acids in water and water-ethanol mixtures $\left[\mathrm{Temp} .=25^{\circ} \mathrm{C}\right.$ and $\left.I=0.1 \mathrm{~mol} \cdot \mathrm{dm}^{-3} \mathrm{NaCl}\right]$.

\begin{tabular}{lcccccccccccc}
\hline \multirow{2}{*}{ AA } & \multicolumn{3}{c}{ Water } & \multicolumn{4}{c}{$30 \% \mathrm{E}-70 \% \mathrm{~W}$} & \multicolumn{3}{c}{$50 \% \mathrm{E}-50 \% \mathrm{~W}$} & \multicolumn{3}{c}{$70 \% \mathrm{E}-30 \% \mathrm{~W}$} \\
& $\log K_{1}$ & $\log K_{2}$ & $\log K_{3}$ & $\log K_{1}$ & $\log K_{2}$ & $\log K_{3}$ & $\log K_{1}$ & $\log K_{2}$ & $\log K_{3}$ & $\log K_{1}$ & $\log K_{2}$ & $\log K_{3}$ \\
\hline Cys & 10.29 & 8.36 & 1.71 & 10.25 & 8.23 & 2.60 & 10.81 & 7.06 & 2.93 & 12.07 & 6.33 & 2.82 \\
Tyr & 10.14 & 9.03 & 2.17 & 10.46 & 9.03 & 2.48 & 10.90 & 9.06 & 3.25 & 10.70 & 8.80 & 2.69 \\
Trp & 9.33 & 2.35 & - & 9.17 & 2.83 & - & 9.05 & 3.21 & - & 8.78 & 2.77 & - \\
Lys & 10.69 & 9.08 & 2.04 & 10.20 & 8.77 & 1.71 & 10.07 & 8.76 & 2.68 & 9.64 & 8.48 & 2.19 \\
His & 9.08 & 6.02 & 1.70 & 8.86 & 6.21 & 3.00 & 8.53 & 5.85 & 2.93 & 8.32 & 5.73 & 2.99 \\
\hline
\end{tabular}

Note. E: ethanol, W: water, Cys = L-cysteine, Tyr = L-tyrosine, Trp = L-tryptophane, Lys = L-lysine, and His = L-histidine. ${ }^{\mathrm{a}}$ Data taken from reference [50]; $\log K_{1}$ : corresponds to 11 species (i.e., $\mathrm{L}^{-}+\mathrm{H}^{+} \rightleftharpoons \mathrm{LH}$ ); $\log K_{2}$ corresponds to 12 species (i.e., $\mathrm{LH}+\mathrm{H}^{+} \rightleftharpoons \mathrm{LH}_{2}^{+}$). The \% is expressed as (volume/Volume).

TABLE 4: Protonation constants of some $\alpha$-amino acids in water and water-ethanol mixtures $\left[\text { Temp. }=25^{\circ} \mathrm{C} \text { and } I=0.1 \mathrm{~mol} \cdot \mathrm{dm}^{-3} \mathrm{NaClO}_{4}\right]^{\mathrm{a}}$.

\begin{tabular}{lcccccccccc}
\hline \multirow{2}{*}{ AA } & \multicolumn{2}{c}{$30 \% \mathrm{E}-70 \% \mathrm{~W}$} & \multicolumn{2}{c}{$40 \% \mathrm{E}-60 \% \mathrm{~W}$} & \multicolumn{2}{c}{$50 \% \mathrm{E}-50 \% \mathrm{~W}$} & \multicolumn{2}{c}{$60 \% \mathrm{E}-40 \% \mathrm{~W}$} & \multicolumn{2}{c}{$70 \% \mathrm{E}-30 \% \mathrm{~W}$} \\
& $\log K_{1}$ & $\log K_{2}$ & $\log K_{1}$ & $\log K_{2}$ & $\log K_{1}$ & $\log K_{2}$ & $\log K_{1}$ & $\log K_{2}$ & $\log K_{1}$ & $\log K_{2}$ \\
\hline Gly & 9.54 & 2.81 & 9.39 & 2.89 & 9.35 & 2.90 & 9.20 & 3.05 & 9.05 \\
Ala & 9.70 & 2.88 & 9.55 & 2.97 & 9.45 & 3.05 & 9.18 & 3.06 & 9.12 & 3.06 \\
Val & 9.50 & 2.85 & 9.41 & 2.95 & 9.30 & 3.15 & 9.07 & 3.16 & 9.02 & 3.17 \\
Leu & 9.60 & 2.87 & 9.40 & 3.01 & 9.30 & 3.06 & 9.07 & 3.17 & 9.05 \\
Ile & 9.55 & 2.92 & 9.47 & 2.98 & 9.31 & 3.15 & 9.20 & 3.17 & 9.10 & 3.25 \\
Phe & 9.12 & 2.75 & 8.95 & 2.95 & 8.79 & 2.98 & 8.70 & 3.05 & 8.60 \\
Ser & 9.18 & 2.88 & 9.00 & 2.87 & 8.77 & 2.89 & 8.68 & 2.91 & 8.66 \\
Met & 9.05 & 2.67 & 8.99 & 2.85 & 8.85 & 2.88 & 8.67 & 3.00 & 8.00 \\
\hline
\end{tabular}

Note. E: ethanol, W: water, Val = L-valine, Ala = L-alanine, Leu = L-leucine, Ile = L-isoleucine, Phe = L-phenylalanine, Ser = L-serine, and Thr = L-threonine; ${ }^{a}$ data taken from reference [49]. $\log K_{1}$ corresponds to 11 species (i.e., $\mathrm{L}^{-}+\mathrm{H}^{+} \rightleftharpoons \mathrm{LH}$ ); $\log K_{2}$ corresponds to 12 species (i.e., $\mathrm{LH}+\mathrm{H}^{+} \rightleftharpoons \mathrm{LH}{ }^{+}$). $T$ he $\%$ is expressed as (volume/Volume).

TABLE 5: Protonation constants of dipeptides in water and water-ethanol mixture $\left[\right.$ Temp. $=25^{\circ} \mathrm{C}$ and $\left.I=0.1 \mathrm{~mol} \cdot \mathrm{dm}^{-3} \mathrm{NaCl}\right]$.

\begin{tabular}{lcccccccc}
\hline \multirow{2}{*}{ Dipeptides } & \multicolumn{2}{c}{ Water } & \multicolumn{2}{c}{$20 \% \mathrm{E}-80 \% \mathrm{~W}^{\mathrm{c}}$} & \multicolumn{2}{c}{$40 \% \mathrm{E}-60 \% \mathrm{~W}^{\mathrm{c}}$} & \multicolumn{2}{c}{$60 \% \mathrm{E}-40 \% \mathrm{~W}^{\mathrm{c}}$} \\
& $\log K_{1}$ & $\log K_{2}$ & $\log K_{1}$ & $\log K_{2}$ & $\log K_{1}$ & $\log K_{2}$ & $\log K_{1}$ & $\log K_{2}$ \\
\hline Gly-Gly & $8.15^{\mathrm{a}}$ & $3.11^{\mathrm{b}}$ & 7.66 & 3.33 & 6.92 & 3.54 & 6.98 \\
GlyVal & $8.23^{\mathrm{d}}$ & $3.15^{\mathrm{d}}$ & 7.67 & 3.52 & 7.06 & 3.91 & 6.92 \\
GlyLeu & $7.91^{\mathrm{e}}$ & $3.15^{\mathrm{e}}$ & 7.60 & 3.38 & 7.17 & 3.94 & 7.02 & 4.18 \\
GlyPhe & $7.98^{\mathrm{d}}$ & $3.03^{\mathrm{d}}$ & 7.62 & 3.33 & 6.96 & 3.65 & 6.98 \\
GlyThr & $8.50^{\mathrm{c}}$ & $3.20^{\mathrm{c}}$ & 7.74 & 3.19 & 7.07 & 3.37 & 7.05 \\
GlyMet & $8.22^{\mathrm{f}}$ & $3.11^{\mathrm{f}}$ & 7.64 & 3.32 & 7.02 & 3.62 & 6.96 \\
\hline
\end{tabular}

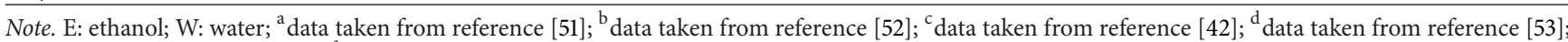
${ }^{\mathrm{e}}$ data taken from reference [54]; ${ }^{\mathrm{f}}$ data taken from reference [55]. $\log K_{1}$ corresponds to 11 species (i.e., $\mathrm{L}^{-}+\mathrm{H}^{+} \rightleftharpoons \mathrm{LH}$ ); $\log K_{2}$ corresponds to 12 species (i.e., $\left.\mathrm{LH}+\mathrm{H}^{+} \rightleftharpoons \mathrm{LH}_{2}^{+}\right)$. The $\%$ is expressed as (volume/Volume). 
TABLE 6: Protonation constants of $\alpha$-amino acid esters in water-ethanol mixtures [Temp. $=25^{\circ} \mathrm{C}$ and $\left.I=0.1 \mathrm{~mol} \cdot \mathrm{dm}^{-3} \mathrm{NaCl}\right]^{\mathrm{a}}$.

\begin{tabular}{lcccccccc}
\hline \multirow{2}{*}{ Esters } & \multicolumn{2}{c}{ Water } & \multicolumn{2}{c}{$30 \% \mathrm{E}-70 \% \mathrm{~W}$} & \multicolumn{2}{c}{$50 \% \mathrm{E}-50 \% \mathrm{~W}$} & \multicolumn{2}{c}{$70 \% \mathrm{E}-30 \% \mathrm{~W}$} \\
& $\log K_{1}$ & $\log K_{2}$ & $\log K_{1}$ & $\log K_{2}$ & $\log K_{1}$ & $\log K_{2}$ & $\log K_{1}$ \\
\hline CysOMe & 9.17 & 6.38 & 9.23 & 6.09 & 9.34 & 5.88 & 10.82 \\
CysOEt & 9.36 & 6.54 & 9.37 & 6.17 & 9.48 & 5.97 & 11.13 \\
TyrOMe & 9.73 & 7.04 & 10.10 & 6.73 & 10.49 & 6.42 & 10.62 \\
TyrOEt & 9.71 & 7.05 & 10.13 & 6.75 & 10.52 & 6.45 & 10.63 \\
TrpOMe & 10.66 & 7.10 & 11.27 & 6.78 & 11.56 & 6.51 & 11.39 \\
TrpOEt & 10.79 & 7.10 & 11.28 & 6.98 & 11.70 & 6.80 & 6.17 \\
LysOMe & 9.99 & 6.98 & 9.80 & 6.90 & 9.52 & 6.63 & 6.19 \\
LysOEt & 10.32 & 7.18 & 9.70 & 6.81 & 9.45 & 6.60 & 9.12 \\
HisOMe & 7.10 & 4.96 & 6.72 & 4.78 & 6.54 & 4.61 & 9.00 \\
\hline
\end{tabular}

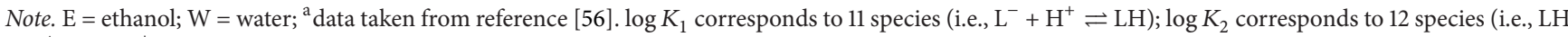
$+\mathrm{H}^{+} \rightleftharpoons \mathrm{LH}_{2}{ }^{+}$). The $\%$ is expressed as (volume/Volume).

TABLE 7: Protonation constants of $\alpha$-amino acid-t-butyl and benzyl esters at $25^{\circ} \mathrm{C}$ for different water-EtOH mixtures $\left[I=0.1 \mathrm{~mol} \cdot \mathrm{dm}^{-3} \mathrm{NaCl}\right]^{\mathrm{a}}$.

\begin{tabular}{|c|c|c|c|c|c|c|c|}
\hline Esters & $\begin{array}{c}20 \% \mathrm{E}-80 \% \mathrm{~W} \\
X=0.0331\end{array}$ & $\begin{array}{c}30 \% \mathrm{E}-70 \% \mathrm{~W} \\
X=0.1167\end{array}$ & $\begin{array}{c}40 \% \mathrm{E}-60 \% \mathrm{~W} \\
X=0.1740\end{array}$ & $\begin{array}{c}50 \% \mathrm{E}-50 \% \mathrm{~W} \\
X=0.2356\end{array}$ & $\begin{array}{c}60 \% \mathrm{E}-40 \% \mathrm{~W} \\
X=0.3161\end{array}$ & $\begin{array}{c}70 \% \mathrm{E}-30 \% \mathrm{~W} \\
X=0.4183\end{array}$ & $\begin{array}{c}80 \% \mathrm{E}-0 \% \mathrm{~W} \\
X=0.5521\end{array}$ \\
\hline GlyO-t-Bu & 7.66 & 7.51 & 7.40 & 7.30 & 7.20 & 7.05 & 6.64 \\
\hline $\mathrm{AlaO}-\mathrm{t}-\mathrm{Bu}$ & 9.01 & 8.86 & 8.75 & 8.55 & 8.39 & 8.16 & 8.14 \\
\hline ValO-t-Bu & 7.74 & 7.56 & 7.15 & 6.95 & 6.85 & 6.51 & 6.50 \\
\hline LeuO-t-Bu & 7.79 & 7.63 & 7.38 & 7.21 & 7.02 & 6.92 & 6.75 \\
\hline PheO-t-Bu & 7.15 & 7.00 & 6.67 & 6.56 & 6.50 & 6.40 & 6.33 \\
\hline IleO-t-Bu & 7.75 & 7.65 & 7.35 & 7.18 & 7.12 & 6.89 & 6.64 \\
\hline GlyO-Bz & 7.27 & - & 7.07 & - & 6.94 & - & 6.85 \\
\hline AlaO-Bz & 7.35 & - & 7.17 & - & 7.01 & - & 7.00 \\
\hline ValO-Bz & 7.16 & - & 6.88 & - & 6.77 & - & 6.68 \\
\hline SerO-Bz & 6.75 & - & 6.60 & - & 6.51 & - & 6.54 \\
\hline
\end{tabular}

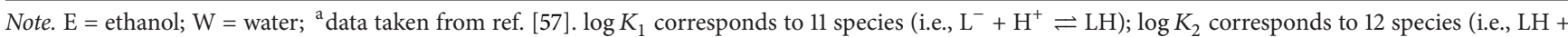
$\mathrm{H}^{+} \rightleftharpoons \mathrm{LH}_{2}{ }^{+}$). The \% is expressed as (volume/Volume).

is better solvated in water than anionic form $\left(\mathrm{L}^{-}\right)$. The reason for the decrease in $\log _{10} K_{2}$ is that solvation of the multicharged species formed by the attachment of a proton to the imidazole ring is very limited in ethanol.

(4) Protonation Equilibria of Some $\alpha$-Amino Acids in Mixed Water-Ethanol Medium. The numerical $\log _{10} K_{1}$ and $\log _{10} K_{2}$ values of eight $\alpha$-amino acids (glycine, $\mathrm{L}$-alanine, $\mathrm{L}$-valine, L-leucine, L-isoleucine, L-phenylalanine, L-serine, and Lmethionine) determined in water-ethanol mixtures are given in Table 4. When the change of $\log _{10} K_{1}$ given in Table 4 with the solvent composition is examined, it is observed that these values decrease with the increase in the mole fraction of ethanol. This can be explained by the structural changes in amino acids as the medium changed toward the ethanolrich direction. The neutral form amino acid HL is subjected to higher solvation compared with $\mathrm{L}^{-}$forms in ethanol rich media. In water-rich media, however, the reverse behavior will be the case. This shows that $\log _{10} K_{1}$ values are expected to decrease with an increase in ethanol ratio. Therefore, one can conclude that the dipolar form of amino acids, $\mathrm{HL}^{ \pm}$, dominates in these media. It is the only way to explain the decrease in $\log _{10} K_{1}$ as the amount of ethanol in the media is increased since $\mathrm{L}^{-}$is expected to solvate more than $\mathrm{HL}^{ \pm}$in media rich in ethanol.
The fact that $\log _{10} K_{2}$ values are observed to increase as the mole fraction of ethanol is increased in all media investigated supports that dipolar ion is predominant in water-ethanol mixtures as well as in water. This is due to the fact that ethanol solvated $\mathrm{H}_{2} \mathrm{~L}$ better than $\mathrm{HL}^{ \pm}$. If the neutral form were the predominant species in water-ethanol mixture, $\log _{10} K_{2}$ values would decrease with increasing amount of ethanol since ethanol solvated $\mathrm{HL}$ better than $\mathrm{H}_{2} \mathrm{~L}^{+}[64,65]$.

3.2.2. Protonation Equilibria of Dipeptides in Mixed WaterEthanol Medium. Two protonation equilibria were found for all glycine-dipeptides (Figure 4) mentioned in Table 5.

The first protonation constant was attributed to the protonation of amino group and the second one was related to the protonation of carboxylate group:

$$
\begin{array}{cc}
\mathrm{L}^{-}+\mathrm{H}^{+} \rightleftharpoons \mathrm{HL} & K_{1}=\frac{[\mathrm{HL}]}{\left[\mathrm{L}^{-}\right]\left[\mathrm{H}^{+}\right]} \\
\mathrm{HL}+\mathrm{H}^{+} \rightleftharpoons \mathrm{H}_{2} \mathrm{~L}^{+} & K_{2}=\frac{\left[\mathrm{H}_{2} \mathrm{~L}^{+}\right]}{[\mathrm{HL}]\left[\mathrm{H}^{+}\right]}
\end{array}
$$

where $\mathrm{L}$ is dipeptide monoanion; $\mathrm{HL}$ is total zwitterion and neutral forms of dipeptide.

Chattopadhyay and Lahiri [66] examined the effect of a change of solvent composition on $\mathrm{BH}^{+}$ionization and the 
<smiles>NCCCCC(N)C(=O)O</smiles>
Lysine (Lys)<smiles>NC(Cc1cnc[nH]1)C(=O)O</smiles>

Histidine (His)

FiguRE 3

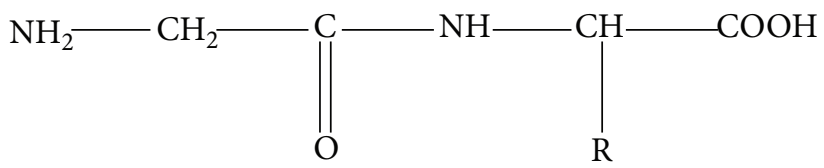

(Dipeptide)

$$
\begin{array}{ll}
\mathrm{R}=\mathrm{H} & \text { (Gly-Gly) } \\
\mathrm{R}=-\mathrm{CH}_{2}-\mathrm{CH}\left(\mathrm{CH}_{3}\right)_{2} & \text { (GlyLeu) } \\
\mathrm{R}=-\mathrm{CH}\left(\mathrm{CH}_{3}\right)_{2} & \text { (GlyVal) } \\
\mathrm{R}=-\mathrm{CH}_{2}-\mathrm{CH}_{2}-\mathrm{S}-\mathrm{CH}_{3} & \text { (GlyMet) } \\
\mathrm{R}=-\mathrm{CH}_{2}-\mathrm{Ph} & \text { (GlyPhe) } \\
\mathrm{R}=-\mathrm{CH}(\mathrm{OH})-\mathrm{CH}_{3} & \text { (GlyThr) }
\end{array}
$$

Figure 4

related Gibbs transfer energies in mixed solvent. They emphasized that the electrostatic charge effects due to changes in the dielectric constants with changes in solvent composition are of minor importance in explaining solvent effects, and that solute-solvent interactions have greater significance in interpretation of solvent effects.

These protonation constants have been considered in some detail to gain more information about the effect of solvent composition on the corresponding equilibria. For this purpose, by examining the protonation equilibria of dipeptides with solvent composition, it is generally observed that $\log _{10} K_{1}$ values decrease with the increase in the mole fraction of ethanol, whereas $\log _{10} K_{2}$ values increase as the composition of ethanol increases in water-ethanol mixture. The decrease in $\log _{10} K_{1}$ values and increase in $\log _{10} K_{2}$ values of all dipeptides with the increasing ethanol concentration were the same as for the corresponding free amino acids [48].

The fact that the variation of $\log _{10} K_{1}$ and $\log _{10} K_{2}$ of dipeptides with solvent composition is similar to those of the corresponding free amino acids and can be concluded from the domination of the zwitterionic form of dipeptides in water-ethanol mixtures. In water-rich media, however, the reverse behavior will be the case. This shows that $\log _{10} K_{1}$ values are expected to increase with an increase in the ethanol ratio. This is the only way which explains the decrease in $\log _{10} K_{1}$ as the amount of ethanol in the media is increased because $\mathrm{L}^{-}$is expected to solvate more than the zwitterionic form of dipeptides in the media rich in ethanol. The fact that $\log _{10} K_{2}$ values are observed to increase as the mole fraction of ethanol is increased in all media investigated supports that dipolar ion is predominant in water-ethanol mixtures as well as in water. This is due to the fact that ethanol solvated $\mathrm{H}_{2} \mathrm{~L}$ better than zwitterionic form. If the neutral form were the predominant species in water-ethanol mixture, $\log _{10} K_{2}$ values would decrease with increasing amount of ethanol because ethanol solvated HL better than $\mathrm{H}_{2} \mathrm{~L}^{+}$. Thus, we can say that the $\log _{10} K_{2}$ values for these dipeptides increase as the mole fraction of ethanol increases.

In order to compare the $\log _{10} K_{1}$ and $\log _{10} K_{2}$ dipeptides with the $\log _{10} K_{1}$ value of glycine and $\log _{10} K_{2}$ value of the other amino acid forming the dipeptide the protonation constants of the corresponding amino acids are given in Table 5. According to the data given in Table 5 , the $\log _{10} K_{2}$ values of amino acids increase and the $\log _{10} K_{1}$ values of glycine decrease due to peptide formation. For instance $\log _{10} K_{1}$ and $\log _{10} K_{2}$ values for glycine in $60 \%$ water- $40 \%$ ethanol medium were 9.39 and 2.89 [55, 67], respectively, while same values were found as 6.92 and 3.54 for Gly-Gly. Similarly $\log _{10} K_{1}$ for glycine was 9.20 [55] and $\log _{10} K_{2}$ for phe was 3.05 [57] in $40 \%$ water- $60 \%$ ethanol medium while these values were observed to be 6.98 and 3.91 for GlyPhe in the same medium. This may be attributed to the fact that the electron density of the amino group in dipeptide is lower than that of glycine, and the electron density of the carboxylate group is higher than that of the corresponding amino acid due to the formation of a peptide bond.

Estimation of equilibrium concentrations of protonligand formation as a function of $\mathrm{pH}$ provides a useful picture of proton-ligand binding in media [16]. Figures 5, 6, 7, and 8 show the change of different species of dipeptides with $\mathrm{pH}$. It is seen from these figures that the most predominant species is HL (total concentration of the zwitterion and the neutral form) between $\mathrm{pH} 5$ and 7 in all ethanol-water media.

3.2.3. Protonation Equilibria of Amino Acid Esters in EthanolWater Medium. The changes of the protonation constants of methyl and ethyl esters of L-tyrosine, L-tryptophane, L-cysteine, L-lysine, and methyl ester of L-histidine with 


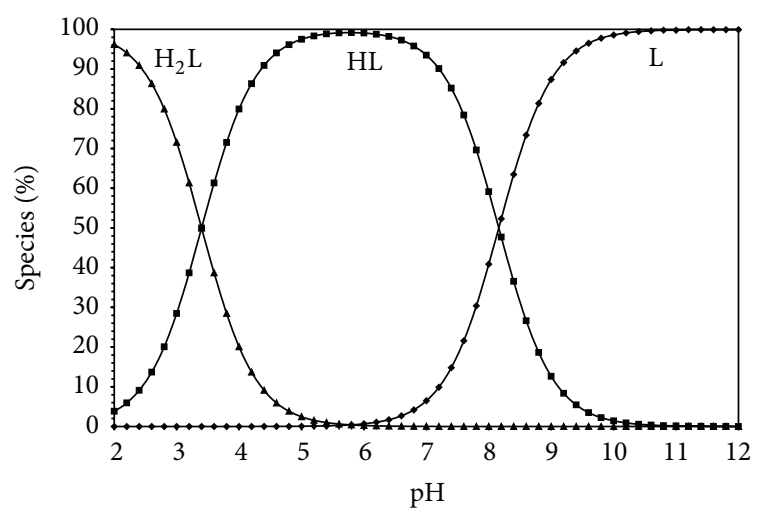

FIgure 5: Species distribution diagram $\left(25^{\circ} \mathrm{C}, I=0.1 \mathrm{M} \mathrm{NaCl}\right)$ for Gly-Gly system as a function of $\mathrm{pH}$ in water $\left(\mathrm{L}=1.5 \times 10^{-3} \mathrm{M}\right)$.

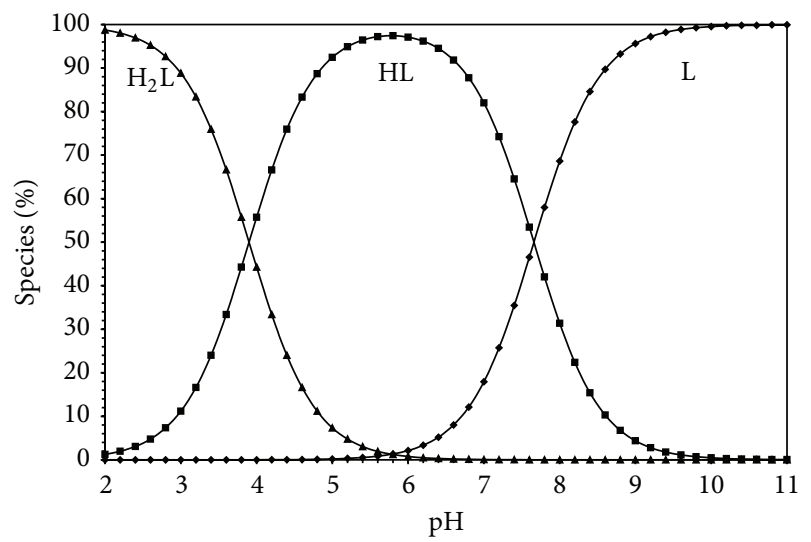

Figure 6: Species distribution diagram $\left(25^{\circ} \mathrm{C}, I=0.1 \mathrm{M} \mathrm{NaCl}\right)$ for Gly-Gly system as a function of $\mathrm{pH}$ in $20 \%$ ethanol- $80 \%$ water $(\mathrm{L}=$ $\left.1.5 \times 10^{-3} \mathrm{M}\right)$.

increasing ethanol percentage are given in Table 6. It can be seen that $\log _{10} K_{1}$ values of L-tyrosine, L-tryptophane, and Lcysteine esters increase with increasing percentage of ethanol. On the other hand, the $\log _{10} K_{2}$ values show a decrease with increasing ethanol concentration. The $\log _{10} K_{1}$ and $\log _{10} K_{2}$ values of L-lysine and L-histidine esters both decrease with increasing ethanol concentration in the solvent mixture.

The protonation constants of methyl and ethyl esters of Lcysteine, L-tyrosine, and L-tryptophane are given in Table 6. The $\log _{10} K_{1}$ values belong to equilibria related to the attachment of $\mathrm{H}^{+}$to the sulfur atom in the thiol group of cysteine esters, to the nitrogen atom in the indole ring of tryptophane, and to the phenolic oxygen group in tyrosine esters. The $\log _{10} K_{2}$ values are related to the protonation of $-\mathrm{NH}_{2}$ groups in the esters. The increase in the ethanol concentration decreases the dielectric constant of the medium. The amino acid ester (HL) is subjected to stronger solvation compared with the $\left(\mathrm{L}^{-}\right)$and $\left(\mathrm{H}_{2} \mathrm{~L}^{+}\right)$forms in ethanol-rich media. In water-rich media, however, the reverse behavior will be the case. This shows that $\log _{10} K_{1}$ values are expected to increase and $\log _{10} K_{2}$ values to decrease with an increase in the ethanol ratio.

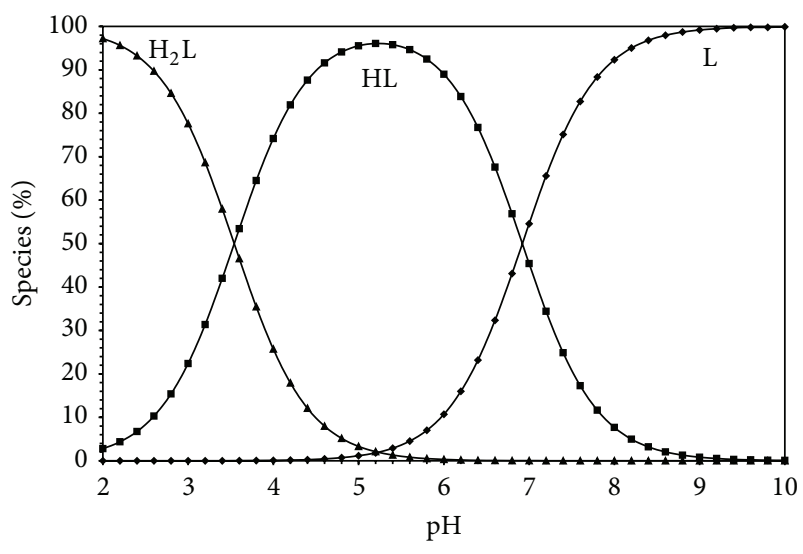

Figure 7: Species distribution diagram $\left(25^{\circ} \mathrm{C}, I=0.1 \mathrm{M} \mathrm{NaCl}\right)$ for Gly-Gly system as a function of $\mathrm{pH}$ in $40 \%$ ethanol- $60 \%$ water $(\mathrm{L}=$ $\left.1.5 \times 10^{-3} \mathrm{M}\right)$.

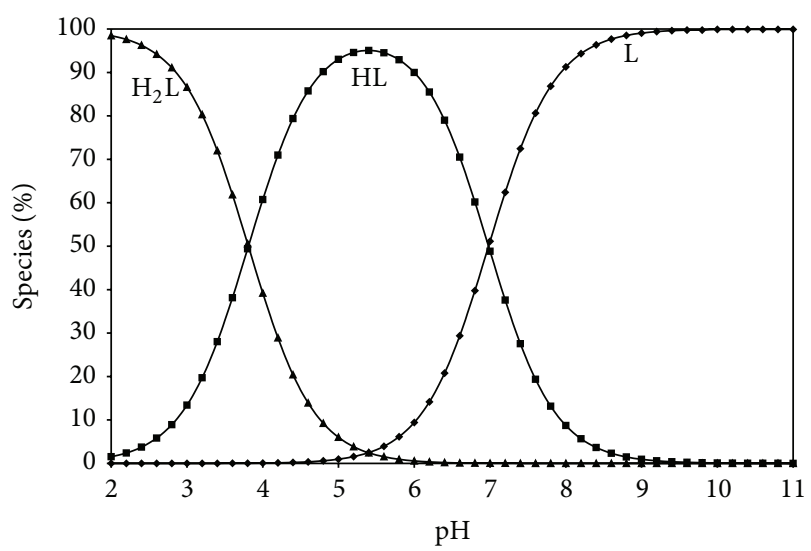

FIgure 8: Species distribution diagram $\left(25^{\circ} \mathrm{C}, I=0.1 \mathrm{M} \mathrm{NaCl}\right)$ for Gly-Gly system as a function of $\mathrm{pH}$ in $60 \%$ ethanol- $40 \%$ water $(\mathrm{L}=$ $\left.1.5 \times 10^{-3} \mathrm{M}\right)$.

The $\log _{10} K_{1}$ and $\log _{10} K_{2}$ values of L-lysine esters are related to the protonation of amino groups in side chain and $\alpha$-amino groups, respectively. For L-histidine esters, these values correspond to the protonation of nitrogen in the imidazole and $\alpha$-amino group in L-histidine. Contrary to the other esters investigated both $\log _{10} K_{1}$ and $\log _{10} K_{2}$ values of lysine methyl and ethyl esters and histidine methyl ester decrease with an increase in the ratio of ethanol in the solvent mixture. Since $\mathrm{H}_{2} \mathrm{~L}^{2+}$ is better solvated than $\mathrm{HL}^{+}$and the latter is better solvated than L-molecular species in waterrich media, therefore, results obtained for these esters can be explained by the specific solvation effect.

The stoichiometric protonation constants for t-butyl esters and benzyl esters of $\alpha$-amino acids determined in ethanol-water mixtures (20-80 volume \% ethanol) are given in Table 7. These values are related to this equilibrium reaction $\mathrm{L}+\mathrm{H}^{+} \rightleftharpoons \mathrm{LH}^{+}$, where $\mathrm{L}$ and $\mathrm{LH}^{+}$show $\alpha$ amino acid esters and their protonated species, respectively. The protonation constants given in Table 7 are considered in more detail in order to gain more information about the effect of solvent composition and specific effects of 
TABLE 8: Protonation constants of some $\alpha$-amino acids in water and water-dioxane mixtures $\left[\text { Temp. }=25^{\circ} \mathrm{C} \text { and } I=0.1 \mathrm{~mol} \cdot \mathrm{dm}^{-3} \mathrm{NaClO}_{4}\right]^{\mathrm{a}}$.

\begin{tabular}{lcccccccccccccc}
\hline \multirow{2}{*}{ AA } & \multicolumn{2}{c}{ Water } & \multicolumn{2}{c}{$10 \% \mathrm{D}-90 \% \mathrm{~W}$} & \multicolumn{2}{c}{$20 \% \mathrm{D}-80 \% \mathrm{~W}$} & \multicolumn{2}{c}{$30 \% \mathrm{D}-70 \% \mathrm{~W}$} & \multicolumn{2}{c}{$40 \% \mathrm{D}-60 \% \mathrm{~W}$} & \multicolumn{3}{c}{$50 \% \mathrm{D}-50 \% \mathrm{~W}$} & \multicolumn{2}{c}{$60 \% \mathrm{D}-40 \% \mathrm{~W}$} \\
& $\log K_{1}$ & $\log K_{2}$ & $\log K_{1}$ & $\log K_{2}$ & $\log K_{1}$ & $\log K_{2}$ & $\log K_{1}$ & $\log K_{2}$ & $\log K_{1}$ & $\log K_{2}$ & $\log K_{1}$ & $\log K_{2}$ & $\log K_{1}$ & $\log K_{2}$ \\
\hline Gly & 9.58 & 2.32 & 9.55 & 2.41 & 9.56 & 2.70 & 9.58 & 2.87 & 9.58 & 3.15 & 9.60 & 3.48 & 9.62 & 3.60 \\
Ala & 9.70 & 2.40 & 9.66 & 2.52 & 9.72 & 2.64 & 9.68 & 2.89 & 9.73 & 3.10 & 9.75 & 3.39 & 9.78 & 3.63 \\
Val & 9.61 & 2.38 & 9.56 & 2.53 & 9.60 & 2.68 & 9.58 & 2.86 & 9.60 & 3.08 & 9.62 & 3.43 & 9.66 & 3.65 \\
Leu & 9.75 & 2.50 & 9.59 & 2.64 & 9.64 & 2.80 & 9.66 & 2.99 & 9.70 & 3.31 & 9.72 & 3.55 & 9.75 & 3.75 \\
Ile & 9.76 & 2.47 & 9.72 & 2.58 & 9.63 & 2.74 & 9.67 & 2.97 & 9.65 & 3.26 & 9.70 & 3.55 & 9.71 & 3.74 \\
Phe & 9.20 & 2.43 & 9.15 & 2.57 & 9.10 & 2.64 & 9.12 & 2.81 & 9.15 & 3.10 & 9.16 & 3.36 & 9.15 & 3.50 \\
Ser & 9.15 & 2.42 & 9.07 & 2.57 & 9.10 & 2.62 & 9.13 & 2.82 & 9.16 & 3.04 & 9.20 & 3.17 & 9.17 & 3.35 \\
Thr & 9.04 & 2.45 & 9.02 & 2.53 & 9.06 & 2.60 & 9.05 & 2.75 & 9.07 & 2.96 & 9.10 & 3.18 & 9.17 & 3.40 \\
\hline
\end{tabular}

Note. $\mathrm{D}=$ dioxane, $\mathrm{W}=$ water, $\mathrm{Val}=\mathrm{DL}$-valine, $\mathrm{Ala}=\mathrm{DL}$-alanine, $\mathrm{Leu}=\mathrm{L}$-leucine, $\mathrm{Ile}=\mathrm{L}$-isoleucine, $\mathrm{Phe}=\mathrm{DL}$-phenylalanine, Ser $=\mathrm{L}$-serine, and Thr $=\mathrm{L}$ threonine. ${ }^{a}$ Data taken from reference [61]. $\log K_{1}$ corresponds to 11 species (i.e., $\mathrm{L}^{-}+\mathrm{H}^{+} \rightleftharpoons \mathrm{LH}$ ); $\log K_{2}$ corresponds to 12 species (i.e., $\mathrm{LH}+\mathrm{H}^{+} \rightleftharpoons \mathrm{LH}_{2}{ }^{+}$). The $\%$ is expressed as (volume/Volume).

substituents on the basicities of the esters in solvent mixtures. The numerical $\log _{10} K$ values for t-butyl esters of $\alpha$-amino acids determined in ethanol-water mixtures decrease with increasing ethanol content in the solvent mixture. It is observed that a nearly linear relationship exists between the aforementioned protonation constants and the mole fraction of ethanol from 0.0331 to 0.4183 for all $\alpha$-amino acid esters investigated. However, $\log \beta$ values at a mole fraction of ethanol of 0.4183 are slightly higher than those expected from the linear trend. The linear variation for all $\alpha$-amino acid esters that are given in Table 7 is very similar to that found for ammonia aliphatic alkyl amines, pyridine, and salicylideneanilines $[68,69]$. The dissociation constants of charged acids in water-ethanol mixtures vary with solvent composition in a manner that is not completely understood. It is suggested that electrostatic charging effects resulting from the change in dielectric constant with solvent effects and the solute-solvent interactions have greater significance in the interpretation of solvent effects. Thus, results obtained for $\alpha$-amino acid esters in water-ethanol medium can be explained by specific solvation effects. Since ethanol would solvate $\mathrm{L}$ better than $\mathrm{LH}^{+}$, the $\log \beta$ values, which are related to the formation of $\mathrm{LH}^{+}$, would decrease upon addition of ethanol. The derivations of linearity in $80 \%$ ethanol may result from the preferential solvation of solute by one of the components of the solvent mixture that could change the effective dielectric constant value in the cybotactic region [70]. Furthermore, another factor which explains the increase in the $\log \beta$ values of all $\alpha$-amino acid esters in ethanolrich regions is the differences in the solvent stabilization of the ionic species $\left(\mathrm{H}^{+}\right.$and $\left.\mathrm{LH}^{+}\right)$, brought about by changing the percentage of ethanol $[5,71]$. Using the protonation constants obtained in this paper, the effects of the type of ester groups on the basicity of the amine groups of $\alpha$-amino acid esters have been discussed. The most important factor that affects the basicity and therefore the protonation constant of a compound is the structural effect. Table 7 showed that the basicity of t-butyl esters of glycine, L-alanine, and L-valine is higher than that of the corresponding benzyl esters of the same amino acids in 20\%-60\% ethanol-water mixtures. This effect can be explained by taking the electronic effect of the t-butyl and benzyl groups investigated into account.
3.3. Protonation Equilibria in Mixed Water-Dioxane Medium. Simple heterocyclic compounds, such as 1,4-dioxane, in pesticides are very important to living organisms and environment. Also, it is well established that the "effective" or "equivalent solution" dielectric constants in protein [72, 73] or active site cavities of enzymes [74] are small compared to that in bulk water. Estimates for the dielectric constants in such locations range from 30 to $70[73,75]$. Hence by using aqueous solutions containing $\sim 10-50 \%$ dioxane, one may expect to simulate to some degree the situation in active site cavities [76] and hence to extrapolate the data to physiological conditions. Mixed solvents such as water-dioxane mixtures provide a better model for in vivo reactions because the mixtures simultaneously show a lesser polar character and are partially aqueous contents, as do all biological systems [2]. On the other hand, water-1,4-dioxane mixtures are a very interesting binary solvent system. These mixtures are a favorite mixed solvent system in which to study association and mobilities of ions, because the dielectric constant can be varied over a large range. Changes in protonation constants upon addition of 1,4-dioxane to aqueous solutions are due to increasing ion-ion interactions resulting from the decreasing dielectric constant and from changes in solvent-ion and solvent-solvent interactions [77-79]. Also, the protonation constant of amino acid esters will be helpful in the determination of the microscopic equilibrium constants of the corresponding amino acids. Protonation constants of some $\alpha$-amino acids at different water-dioxane mixtures are given in Tables 8 and 9 [49, 67].

\subsubsection{Protonation Equilibria of $\alpha$-Amino Acids in Mixed Diox-} ane-Water Medium. The stoichiometric protonation constants of eight $\alpha$-amino acids determined in various waterdioxane mixtures are listed in Table 8 . The $\log _{10} K_{1}$ and $\log _{10} K_{2}$ values given in Table 8 refer to the protonation equilibria shown in Figure 9, respectively.

Many studies have shown that the equilibrium constant is linearly related to the fraction of organic solvent [80-83]. The results obtained in this study confirm this observation. Regarding the variation of $\log _{10} K_{1}$ values with the solvent composition, one can postulate that the zwitterionic to neutral form ratio decreases as the dioxane content increases. 
TABLE 9: Protonation constants of $\alpha$-amino acid esters in water-1,4-dioxane mixtures [Temp. $=25^{\circ} \mathrm{C}$ and $\left.I=0.1 \mathrm{~mol} \cdot \mathrm{dm}{ }^{-3} \mathrm{NaCl}\right]^{\mathrm{a}}$.

\begin{tabular}{|c|c|c|c|c|c|c|}
\hline \multirow[t]{2}{*}{ Esters } & \multirow[t]{2}{*}{$p$} & \multirow[t]{2}{*}{$q^{\mathrm{a}}$} & \multirow{2}{*}{$\begin{array}{l}\text { Water } \\
\log K \\
\end{array}$} & \multirow{2}{*}{$\begin{array}{c}20 \% \mathrm{D}-80 \% \mathrm{~W} \\
(X=0.05) \\
\log K\end{array}$} & \multirow{2}{*}{$\begin{array}{c}40 \% \mathrm{D}-60 \% \mathrm{~W} \\
(X=0.12) \\
\log K\end{array}$} & \multirow{2}{*}{$\begin{array}{c}60 \% \mathrm{D}-40 \% \mathrm{~W} \\
(X=0.24) \\
\log K\end{array}$} \\
\hline & & & & & & \\
\hline GlyO-Me & 1 & 1 & 7.67 & 7.47 & 7.18 & 6.85 \\
\hline GlyO-t-Bu & 1 & 1 & 8.38 & 8.21 & 7.91 & 6.97 \\
\hline ValO-Me & 1 & 1 & 7.53 & 7.38 & 7.09 & 6.08 \\
\hline ValO-Et & 1 & 1 & 8.86 & 8.01 & 7.15 & 6.58 \\
\hline ValO-t-Bu & 1 & 1 & 9.05 & 8.54 & 7.71 & 7.13 \\
\hline SerO-Me & 1 & 1 & 7.10 & 6.99 & 6.69 & 6.61 \\
\hline SerO-Et & 1 & 1 & 7.46 & 7.25 & 6.84 & 6.79 \\
\hline LeuO-Me & 1 & 1 & 7.66 & 7.47 & 7.19 & 6.32 \\
\hline LeuO-Et & 1 & 1 & 7.75 & 7.78 & 7.31 & 6.73 \\
\hline LeuO-t-Bu & 1 & 1 & 7.89 & 8.04 & 7.60 & 6.95 \\
\hline PheO-Me & 1 & 1 & 7.11 & 6.66 & 6.42 & 6.01 \\
\hline PheO-Et & 1 & 1 & 8.12 & 7.24 & 6.81 & 6.24 \\
\hline PheO-t-Bu & 1 & 1 & 8.26 & 7.39 & 6.96 & 6.64 \\
\hline
\end{tabular}

Note. $\mathrm{D}=$ dioxane, $\mathrm{W}=$ water; ${ }^{\mathrm{a}}$ data taken from ref. [44]. $\log K_{1}$ corresponds to 11 species (i.e., $\mathrm{L}^{-}+\mathrm{H}^{+} \rightleftharpoons \mathrm{LH}$ ).<smiles>[R]C(N)C(=O)[O-]</smiles>

(anionic form, $\mathrm{L}^{-}$)<smiles>[R]C(N)C(=O)O</smiles>

$K_{1}=\frac{\left([\mathrm{HL}]+\left[\mathrm{H}^{+} \mathrm{L}^{-}\right]\right)}{\left[\mathrm{L}^{-}\right]\left[\mathrm{H}^{+}\right]}$<smiles>[R]C(N)C(=O)O</smiles>

(dipolar ion, $\mathrm{HL}^{ \pm}$)

(neutral form, HL) 
where $\mathrm{B}$ and $\mathrm{BH}^{+}$denote the $\alpha$-amino acid esters and their protonated species, respectively. The protonation constants given in Table 9 were considered in more detail in order to gain more information about the effect of solvent composition and specific effects of substituents on the basicities of the esters in solvent mixtures. When it comes to the variation of $\log \beta$ with the solvent composition, it can be observed that these constants decrease as the concentration of 1,4-dioxane increases in going from water to $60 \%$ in dioxane-water mixtures. It is also observed that a nearly linear relationship exists between the protonation constants and the mole fraction of 1,4-dioxane between 0.05 and 0.24 for all $\alpha$-amino acid esters investigated. Many studies have shown that the equilibrium constant is linearly related to the fraction of organic solvent [80-83]. Although the effect of solvent composition upon the protonation constants of various compounds has been the subject of extensive investigation, the variation of charged acid-base equilibrium constants with solvent composition is yet to be fully elucidated. The solvation of a solute in a mixed solvent is much more complicated than solvation in a single pure solvent, and in the literature there are several different explanations. In organic solvent-water mixtures, acid-base equilibria can be estimated from two effects: an electrostatic one that can be explained by the Barron equation and a nonelectrostatic one that includes specific solutesolvent interaction [85]. Bates [71] and Chattopadhyay and Lahiri [66] have examined the effect of changing solvent composition on ionization of $\mathrm{BH}^{+}$and the related Gibbs energies of transfer in mixed solvents, and they found that the dielectric constant alone cannot serve for a quantitative explanation for the solvent effect $[66,71]$. However, the solvent mixtures are characterized by dramatic changes in the physical constants of the solvent (i.e., their melting and boiling point, dielectric constants, etc.) and macroscopic solvent parameters (mole fraction of cosolvent, etc.), upon changes of their compositions that influence many solute properties of these mixtures. Also, according to Takamuku et al. [86], the 1,4-dioxane-water mixtures can be divided into three mole fraction ranges, that is, $0.3 \leq X_{\text {dioxane }} \leq 0.9$, $X_{\text {dioxane }}, 0.1 \leq X_{\text {dioxane }} \leq 0.2$, and $0 \leq X_{\text {dioxane }} \leq 0.07$. When $0.3 \leq X_{\text {dioxane }} \leq 0.9$, the structure observed for pure dioxane obviously remains the same as it is mixed with $0.1 \leq X_{\text {dioxane }} \leq 0.2$, small binary clusters consisting of one or two 1,4-dioxane molecules and several water molecules are formed by hydrogen bonding. When $0 \leq X_{\text {dioxane }} \leq$ 0.07 , first-, second-, and third-neighbor $\mathrm{O} \cdots \mathrm{O}$ interactions are observed due to the hydrogen-bonded network of water. This suggests that the addition of a small amount of 1,4dioxane breaks down the hydrogen-bonded network of water. In dioxane-rich mixtures the protonated base $\left(\mathrm{BH}^{+}\right)$is mostly solvated by the less basic dioxane molecules, whereas the proton is more solvated in the water-dioxane mixtures than in water and dioxane, because the water-dioxane mixture is more basic than either pure water or dioxane. Also, the molecular composition of the solvation layer around a solute molecule is not the same as that of the bulk mixture ratio of water to organic solvent. The hydrophobic and hydrophilic properties of a solute may be reflected in preferential solvation in such mixed solvents. Therefore, the influence that the solvent exerts on the $\mathrm{pK}$ values depends upon the extent and nature of the solute-solvent interactions, which involves species participating in the acid-base equilibrium [72]. From the theoretical explanation mentioned above, we can explain results for all $\alpha$-amino acid esters in terms of specific solvation effects. A study of specific solvation effects on the $\alpha$-amino acid esters showed that the $\log _{10} K$ values show a decrease upon increase of the 1,4-dioxane ratio for all $\alpha$-amino acid esters investigated. Because 1,4-dioxane should solvate $\mathrm{B}$ better than $\mathrm{BH}^{+}$, the $\log _{10} \mathrm{~K}$ values, which are related to the formation of $\mathrm{BH}^{+}$, should decrease upon addition of 1,4-dioxane. We can say that the deviations from the trend with the $\log \beta$ values for all amino acid esters appeared in 1,4dioxane-rich regions $(x=0.24)$, resulting from differences in solvent stabilization of the ionic species $\left(\mathrm{H}^{+}\right.$and $\left.\mathrm{BH}^{+}\right)$ being brought about by changing the percentage of 1,4dioxane. The results show that each methyl ester is generally a slightly weaker base than its corresponding ethyl and tbutyl analogues. In addition, the alanine methyl ester is a weaker base than its benzyl ester. The acidity or basicity of a compound in a given medium is influenced by both the electronic effect of substituents and the solvent effect of the medium. Moreover, it is sometimes extremely difficult to assess how much each effect contributes to the acidity or basicity. In the literature it has also been shown that the methyl derivatives of aliphatic amines are weaker bases than their ethyl derivatives in water-methanol mixtures [49]. We can say that the basicity of a compound is a result of various factors such as

(i) the solvent effect (solvation power, the tendency of forming hydrogen bonds, selective solvation, dielectric constant, and the composition of the solution in the first solvation layer) in the case of mixed solvents,

(ii) structural effects, electronic effects, and steric effects.

3.3.3. Protonation Equilibria of DNA in Mixed Water-Dioxane Medium. The solvent effect on the acid dissociation constants of a ligand [87] can be summarized as follows.

(i) As the solvent dielectric constant decreases, the $\log _{10} K$ of the ligand increases and vice versa.

(ii) On decreasing the extent of hydrogen bonding in water by an organic solvent, the proton-accepting properties of the water increase, and consequently the $\log _{10} K$ of the ligand decreases.

(iii) Increasing proton solvation by an organic solvent is accompanied by a decrease in the $\log _{10} K$ of ligand.

The protonation constants of inosine and inosine $5^{\prime}$-monophosphate (Figure 10) as representative examples of DNA constituents in different compositions of dioxane-water mixtures reveal the following features (Table 10) [88]: $\mathrm{pK}_{\mathrm{a}}(\mathrm{N} 1 \mathrm{H})$ of inosine increases linearly with increasing percentage of organic solvent in the medium, Figure 11. This may be correlated with the ability of a solvent of relatively low dielectric constant to increase the electrostatic forces between the proton and the ligand anion and consequently the $\log _{10} K$ value increases. The same trend was observed for the 
<smiles>O=c1[nH]cnc2c1ncn2C1OC(CO)C(O)C1O</smiles>

Inosine<smiles>O=c1[nH]cnc2c1ncn2C1OC(COP(=O)([O-])[O-])C(O)C1O</smiles>

Inosine $5^{\prime}$-monophosphate

FIgURE 10

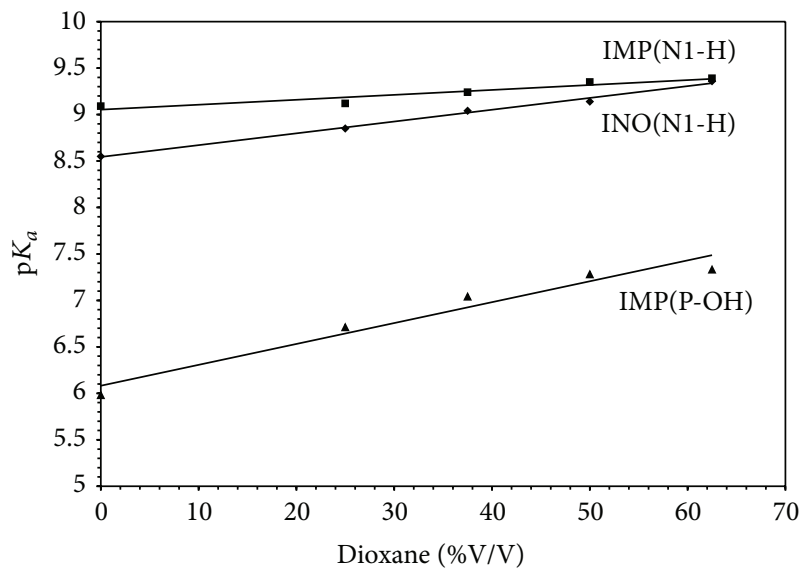

FIGURE 11: Effect of dioxane on the $\mathrm{p} K_{\mathrm{a}}$ of inosine and inosine $5^{\prime}$ monophosphate (IMP).

$\log _{10} K$ 's of $(\mathrm{N} 1 \mathrm{H})$ and phosphoric acid (P-OH) groups of IMP, Figure 11. The $\log _{10} K$ of the phosphate group in IMP is more affected by replacement of water molecules with dioxane. This is in agreement with the above finding, namely, the existence of hydrogen bonds between water molecules and phosphate ions. Thus, the phosphate ions are easily protonated in going from water to dioxane.

\subsection{Protonation Equilibria in Mixed Water-DMSO Medium.}

The use of this mixed solvent has some advantages over pure DMSO. Thus, pure DMSO is very hygroscopic and controlling its water content is difficult [89]. This fact would affect reproducibility of experimental results. However, waterDMSO 50\% : 50\% mixture has only small hygroscopic character. A further advantage is its compatibility with the standard glass electrode, so that the $\mathrm{pH}$ measurements may be carried out in a similar way to that employed in a purely aqueous solution. In contrast, the use of pure DMSO is not recommended for potentiometry. Another advantage of the water-DMSO $50 \%: 50 \%$ mixture is its large acidity range $\left(\mathrm{pK}_{\mathrm{w}}=15.50\right)$ which allows the investigation of deprotonation equilibria of weak acids which could be hardly studied in water $[90,91]$. Protonation constants of some $\alpha$-amino acids at different water-DMSO mixtures and different temperatures are given in Tables 11 and 12 [92, 93].
TABLE 10: Protonation constants of inosine and IMP in dioxanewater media at $25^{\circ} \mathrm{C}$ and $I=0.1 \mathrm{~mol} \cdot \mathrm{dm}^{-3} \mathrm{NaCl}$.

\begin{tabular}{lcccc}
\hline System & \% dioxane & $p$ & $q^{\mathrm{a}}$ & $\log \beta^{\mathrm{b}}$ \\
\hline \multirow{3}{*}{ Inosine IMP } & & 1 & 1 & 8.55 \\
& $0 \%$ & 1 & 1 & 9.09 \\
& & 1 & 2 & 15.07 \\
\hline \multirow{2}{*}{ Inosine IMP } & $25 \%$ & 1 & 1 & 8.85 \\
& & 1 & 1 & 9.12 \\
& & 1 & 2 & 15.83 \\
\hline \multirow{3}{*}{ Inosine IMP } & $37.5 \%$ & 1 & 1 & 9.04 \\
& & 1 & 1 & 9.24 \\
& & 1 & 2 & 16.28 \\
\hline \multirow{3}{*}{ Inosine IMP } & $50 \%$ & 1 & 1 & 9.14 \\
& & 1 & 1 & 9.35 \\
& & 1 & 2 & 16.63 \\
\hline \multirow{3}{*}{ Inosine IMP } & $62.5 \%$ & 1 & 1 & 9.36 \\
& & 1 & 1 & 9.39 \\
& & 1 & 2 & 16.72 \\
\hline
\end{tabular}

${ }^{a} p$ and $q$ are stoichiometric coefficients corresponding to ligand and $\mathrm{H}^{+}$, respectively; ${ }^{\mathrm{b}}$ data taken from reference [83], ${ }^{\mathrm{c}} \mathrm{IMP}=$ inosine $5^{\prime}$ monophosphate. The \% is expressed as (volume/Volume). Species 11 refers to $\mathrm{L}^{-}+\mathrm{H}^{+} \rightleftharpoons \mathrm{LH}$; species 12 refers to $\mathrm{L}+2 \mathrm{H}^{+} \rightleftharpoons \mathrm{LH}_{2}{ }^{+}$.

3.4.1. Protonation Equilibria of Amino Acids in Water-DMSO Medium. The stoichiometric protonation constants of glycine, L-alanine, L-phenylalanine, L-threonine, and L-methionine in water-DMSO mixtures are given in Table 11. The protonation constants $K_{1}$ and $K_{2}$ are related to the protonation of the amino nitrogen and the carboxyl oxygen, respectively. When the change of $\log _{10} K_{1}$ with the solvent composition, given in Table 11, is examined for $\alpha$-amino acids, it is observed that these values increase with an increasing percent of dimethyl sulfoxide. The linear relation is given in Figure 12, for glycine as a representative example of $\alpha$-amino acids. This can be explained by structural changes in the amino acids as the medium becomes more like dimethyl sulfoxide. The neutral form of the amino acids (HL) is subjected to a larger amount of solvation, compared to the anionic form $\left(\mathrm{L}^{-}\right)$in dimethyl sulfoxide rich media. In water-rich media, however, the reverse will be the case.

Also, the $\log _{10} K_{2}$ values increase for each $\alpha$-amino acid as the percentage of dimethyl sulfoxide in the solvent mixtures increases. Many studies have shown that the equilibrium constant is linearly related to the fraction of the organic solvent $[80,81,83]$. In general, the protonation of compounds containing $\mathrm{O}-\mathrm{H}$ increases with increasing organic content of the solvent, due to the decrease in the dielectric constant of the bulk solvents. As the dielectric constant decreases, the ion-ion interaction involving the proton and the anionic oxygen donor of the ligand increases to a greater extent than the ion-dipole interaction between the proton and the solvent molecule. Thus the $\log _{10} K$ of carboxylic acid $\left(\mathrm{COO}^{-} \mathrm{H}^{+}\right)$ groups of $\alpha$-amino acids increases linearly with increasing percentage of organic solvent in the medium. The same trend was observed for the $\mathrm{p} K_{\mathrm{a}}$ 's of phosphoric acid $(\mathrm{P}-\mathrm{OH})$ groups of IMP [88]. 


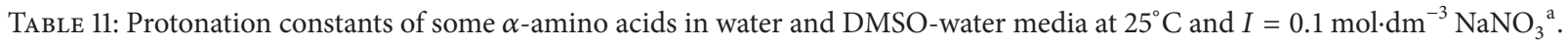

\begin{tabular}{|c|c|c|c|c|c|}
\hline System & $p$ & $q^{\mathrm{b}}$ & $30 \%$ DMSO & $50 \%$ DMSO & $70 \%$ DMSO \\
\hline \multirow{2}{*}{ Gly } & 1 & 1 & $9.51 \pm 0.01$ & $9.79 \pm 0.01$ & $10.29 \pm 0.01$ \\
\hline & 1 & 2 & $12.92 \pm 0.01$ & $13.85 \pm 0.02$ & $15.20 \pm 0.01$ \\
\hline \multirow{2}{*}{ L-Ala } & 1 & 1 & $9.65 \pm 0.009$ & $9.85 \pm 0.02$ & $10.48 \pm 0.02$ \\
\hline & 1 & 2 & $13.07 \pm 0.01$ & $13.96 \pm 0.03$ & $15.36 \pm 0.03$ \\
\hline \multirow{2}{*}{ L-Val } & 1 & 1 & $9.34 \pm 0.01$ & $9.57 \pm 0.01$ & $9.99 \pm 0.01$ \\
\hline & 1 & 2 & $12.61 \pm 0.02$ & $13.61 \pm 0.02$ & $14.88 \pm 0.03$ \\
\hline \multirow{2}{*}{ L-Ser } & 1 & 1 & $8.95 \pm 0.01$ & $9.12 \pm 0.02$ & $9.89 \pm 0.01$ \\
\hline & 1 & 2 & $12.16 \pm 0.02$ & $12.95 \pm 0.03$ & $14.71 \pm 0.03$ \\
\hline \multirow{2}{*}{ L-Isl } & 1 & 1 & $9.31 \pm 0.01$ & $9.51 \pm 0.02$ & $9.91 \pm 0.02$ \\
\hline & 1 & 2 & $12.75 \pm 0.01$ & $13.56 \pm 0.03$ & $15.02 \pm 0.03$ \\
\hline \multirow{2}{*}{ L-Leu } & 1 & 1 & $9.46 \pm 0.01$ & $9.77 \pm 0.05$ & $10.18 \pm 0.01$ \\
\hline & 1 & 2 & $12.80 \pm 0.02$ & $13.81 \pm 0.05$ & $14.98 \pm 0.02$ \\
\hline \multirow{2}{*}{ L-Phe } & 1 & 1 & $9.06^{\mathrm{d}}$ & $9.35^{\mathrm{c}}$ & \multirow{2}{*}{-} \\
\hline & 1 & 2 & 12.44 & 13.43 & \\
\hline \multirow{2}{*}{ L-Met } & 1 & 1 & $9.07^{\mathrm{d}}$ & $9.48^{c}$ & \multirow{2}{*}{-} \\
\hline & 1 & 2 & 12.69 & 13.48 & \\
\hline \multirow{2}{*}{ L-Thr } & 1 & 1 & $8.95^{\mathrm{d}}$ & $9.32^{c}$ & \multirow{2}{*}{-} \\
\hline & 1 & 2 & 12.30 & 13.38 & \\
\hline
\end{tabular}

${ }^{\mathrm{a}}$ Data taken from reference [87]; ${ }^{\mathrm{b}} \mathrm{p}$ and $q$ are stoichiometric coefficients corresponding to ligand and $\mathrm{H}^{+}$, respectively; ${ }^{\mathrm{c}}$ data taken from reference [88]. Species 11 refers to $\mathrm{L}^{-}+\mathrm{H}^{+} \rightleftharpoons \mathrm{LH}$; species 12 refers to $\mathrm{L}+2 \mathrm{H}^{+} \rightleftharpoons \mathrm{LH}_{2}{ }^{+}$; the $\%$ is expressed as (volume/Volume).

TABLE 12: Protonation constants $\left(\log _{10} \beta_{q, r}\right)$ of some $\alpha$-amino acids in solution containing 50\% DMSO at different temperatures and $I=$ $0.1 \mathrm{~mol} \cdot \mathrm{dm}^{-3} \mathrm{NaNO}_{3}$ and their thermodynamic parameters ${ }^{\mathrm{b}}$.

\begin{tabular}{|c|c|c|c|c|c|c|c|c|c|}
\hline \multirow{2}{*}{ System } & \multirow{2}{*}{$p$} & \multirow{2}{*}{$q^{\mathrm{a}}$} & \multirow{2}{*}{$20^{\circ} \mathrm{C}$} & \multirow{2}{*}{$25^{\circ} \mathrm{C}$} & \multirow{2}{*}{$30^{\circ} \mathrm{C}$} & \multirow{2}{*}{$35^{\circ} \mathrm{C}$} & \multicolumn{3}{|c|}{ Thermodynamics $^{\mathrm{d}}$} \\
\hline & & & & & & & $\Delta H^{\circ}$ & $\Delta S^{\circ}$ & $\Delta G^{\circ}$ \\
\hline \multirow{2}{*}{ Gly } & 1 & 1 & 10.04 & 9.79 & 9.53 & 9.30 & -85.71 & -100.14 & -55.87 \\
\hline & 1 & 2 & 14.14 & 13.85 & 13.52 & 13.22 & -21.04 & 6.87 & -23.09 \\
\hline \multirow{2}{*}{ L-Ala } & 1 & 1 & 10.02 & 9.85 & 9.69 & 9.46 & -63.51 & -24.63 & -56.17 \\
\hline & 1 & 2 & 14.19 & 13.96 & 13.75 & 13.46 & -19.34 & 13.80 & -23.46 \\
\hline \multirow{2}{*}{ L-Val } & 1 & 1 & 9.79 & 9.57 & 9.49 & 9.26 & -57.69 & -9.63 & -54.82 \\
\hline & 1 & 2 & 13.89 & 13.61 & 13.47 & 13.17 & -21.75 & 4.31 & -23.03 \\
\hline \multirow{2}{*}{ L-Ser } & 1 & 1 & 9.42 & 9.12 & 8.82 & 8.52 & -103.66 & -173.88 & -52.02 \\
\hline & 1 & 2 & 13.30 & 12.95 & 12.60 & 12.25 & -17.28 & 15.34 & -21.85 \\
\hline \multirow{2}{*}{ L-Isl } & 1 & 1 & 9.72 & 9.51 & 9.39 & 9.20 & -58.07 & -12.28 & -55.74 \\
\hline & 1 & 2 & 13.81 & 13.56 & 13.42 & 13.19 & -11.06 & 40.55 & -23.01 \\
\hline \multirow{2}{*}{ L-Leu } & 1 & 1 & 10.09 & 9.77 & 9.45 & 9.13 & -110.57 & -184.0 & -55.74 \\
\hline & 1 & 2 & 14.18 & 13.81 & 13.42 & 13.04 & -21.07 & 6.51 & -32.01 \\
\hline
\end{tabular}

${ }^{\mathrm{a}} \mathrm{DMSO} \%$ (vol/vol), ${ }^{\mathrm{b}}$ data taken from reference [87], ${ }^{\mathrm{c}} q$ and $r$ are stoichiometric coefficients corresponding to ligand and $\mathrm{H}^{+}$respectively; ${ }^{\mathrm{d}}$ With respect to the thermodynamic parameters $\left(\Delta H^{\circ}, \Delta S^{\circ}\right.$ and $\left.\Delta G^{\circ}\right)$ these parameters referred to these reactions $\left(\mathrm{L}^{-}+\mathrm{H}^{+} \rightleftharpoons \mathrm{LH}^{ \pm}\right.$, corresponding to $-\mathrm{NH}_{2}$ group) and $\left(\mathrm{LH}^{ \pm}+\right.$ $\mathrm{H}^{+} \rightleftharpoons \mathrm{LH}_{2}{ }^{+}$, corresponding to carboxylate group); The \% is expressed as (volume/Volume).

Serine is $\alpha$-amino acid containing three functional groups $\left(-\mathrm{OH},-\mathrm{NH}_{2}\right.$, and $\left.\mathrm{COOH}\right)$, but only two protonation equilibria are determined corresponding to the protonation of amino and carboxylate groups, respectively. This can be attributed to the fact that, as the relative $\mathrm{pH}$ in most experiments did not extend to $\mathrm{pH}>12$, the protonation constant for the aliphatic $\mathrm{OH}$ group in serine could not be measured. Also, a qualitative explanation could be based on the formation of an intramolecular hydrogen bond as depicted in Figure 13. Assume that the proton on this $-\mathrm{OH}$ group is more difficult to remove in the amino acid form.
Also, the $\log _{10} K_{2}$ values increase for each $\alpha$-amino acid as the percentage of dimethyl sulfoxide in the solvent mixtures increases. Many studies have shown that the equilibrium constant is linearly related to the fraction of the organic solvent $[80,81,83]$.

3.5. Thermodynamic Quantities Associated with the Protonation Equilibria. Changes in the temperature may have some significant influences on the equilibrium properties and cause spontaneous changes in aquatic systems. Solution equilibria may be shifted to the right or to the left by an increase in 


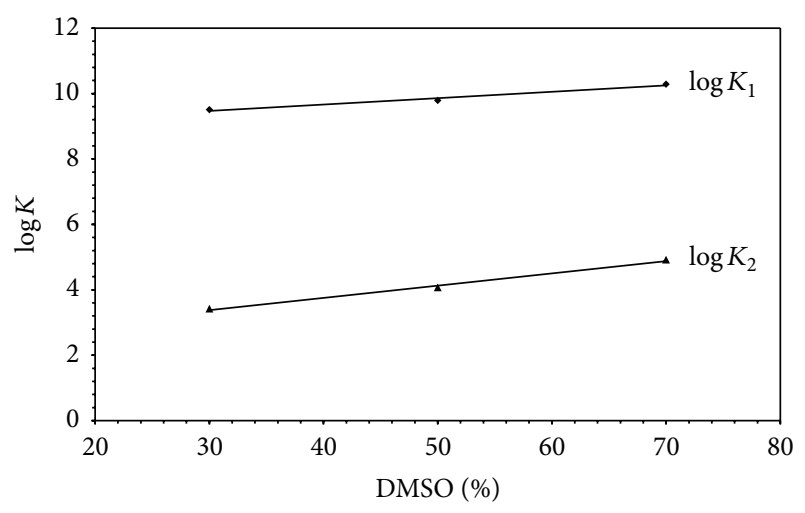

FIGURE 12: The variation of protonation constants of glycine with the percentage of DMSO.<smiles>CC1O[CH]OC(=O)C1[NH3+]</smiles>

(I)

Figure 13: Intramolecular H-bond of serine.

temperature. The direction and magnitude of the shift are given by the sign and magnitude of the heat of the reaction as a function of temperature.

The thermodynamic parameters are useful tools for studying these interactions with bioligands and understanding the relative stability of the formed complexes.

The enthalpy changes accompanying complex formation can be obtained directly through calorimetric measurements, or indirectly from the temperature dependence of the stability constants via the Van't Hoff equation. The accuracy of $\Delta H$ values based on calorimetric measurements is generally higher than the accuracy of those based on the temperature dependence of $\log _{10} K$ values. However, many parameters influence the accuracy of calorimetric data, for example, the enthalpy of dissociation of water, the heat of dilution, and so forth [93].

Application of the temperature dependence of $\log _{10} K$ generally requires the determination of very accurate stability constants over as wide range in temperature as possible. However, the wider the range employed, the greater the uncertainty in the calculated values, because of the temperature dependence of the enthalpy values.

A high electrolyte concentration was used in order to keep variations of the activity coefficients at a minimum. Precise thermodynamic data can only be obtained provided that an inert electrolyte of fairly high concentration $\left(\geq 0.1 \mathrm{~mol} \cdot \mathrm{dm}^{-3}\right)$ is used. The main differences between different procedures for the study of ionic equilibria in aqueous and nonaqueous solutions are due to the activity coefficients. As in most equilibria in nonaqueous medium, a background electrolyte is added to maintain constant ionic strength ranging from

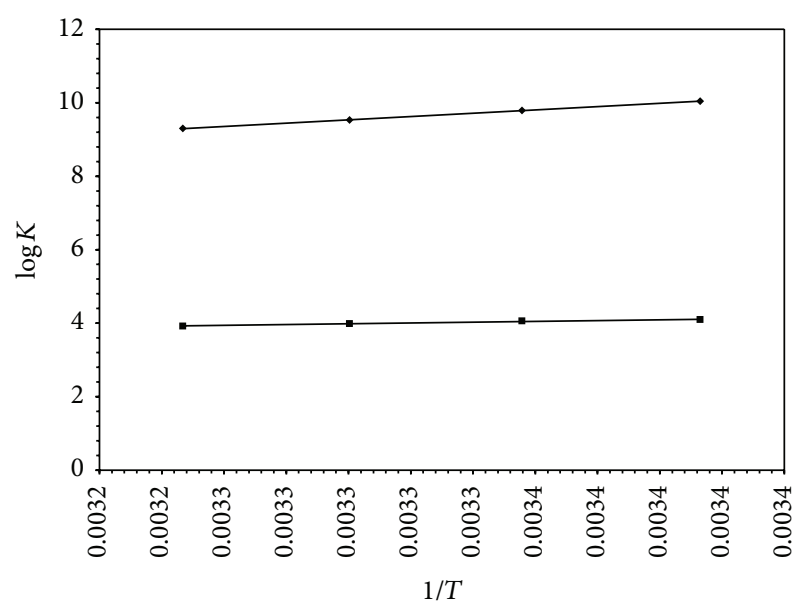

- $\log K_{1}$

- $\log K_{2}$

Figure 14: Van't Hoff plot of $\log K$ of glycine in 50\% DMSO$50 \% \mathrm{H}_{2} \mathrm{O}$ mixture (log $K_{1}$ denotes protonation of amino group and $\log K_{2}$ denotes protonation of carboxylate group).

about 0.1 to $0.3 \mathrm{~mol} \cdot \mathrm{dm}^{-3}$. This is allowed in some waterethanol or water-dioxane mixtures, but not in solvents of low dielectric constants where the solubility of electrolyte is very low. In rigorous thermodynamic calculations, the equilibrium constant should be expressed in terms of activities of the component ions at equilibrium. However, for convenience, concentrations are generally used, where, for a particular species $i, a_{i}=\left(C_{i}\right) F_{i}$, where $C_{i}$ is the concentration of the ion $i, a_{i}$ is its activity, and $F_{i}$ is its activity coefficient. The activity coefficients are maintained constant by working in a medium of constant ionic strength.

The results are summarized in Tables 12 and 13 and can be interpreted as follows.

(1) The protonation reactions $\left(\mathrm{L}^{-}+\mathrm{H}^{+} \rightleftharpoons \mathrm{LH}^{ \pm}\right.$, corresponding to $-\mathrm{NH}_{2}$ group) and $\left(\mathrm{LH}^{ \pm}+\mathrm{H}^{+} \rightleftharpoons \mathrm{LH}_{2}{ }^{+}\right.$, corresponding to carboxylate group) in Table 12 of the investigated amino acids are exothermic (Figure 14). Three factors affect these protonation reactions:

(i) the neutralization reaction, which is an exothermic process,

(ii) desolvation of ions, which is an endothermic process,

(iii) the change in the configuration and the arrangement of the hydrogen bonds around the free and protonated ligands.

(2) The $\log _{10} K$ values decrease with increasing temperature revealing that the acidity increases with increasing temperature (Tables 12 and 13).

The protonation reactions (1) and (2) in Table 13 [88] of the N1 site of inosine and inosine $5^{\prime}$-monophosphate are exothermic. 
TABLE 13: Effect of temperature and thermodynamic parameters of protonation equilibria of inosine and IMP ${ }^{\mathrm{a}}$.

\begin{tabular}{|c|c|c|c|c|c|c|c|c|}
\hline System & $T\left({ }^{\circ} \mathrm{C}\right)$ & $p$ & $q^{\mathrm{b}}$ & $\log \beta$ & Equilibrium & $\begin{array}{c}\Delta H^{\circ} \\
\left(\mathrm{kJ} \mathrm{mol}^{-1}\right)\end{array}$ & $\begin{array}{c}\Delta S^{\circ} \\
\left(\mathrm{JK}^{-1} \mathrm{~mol}^{-1}\right)\end{array}$ & $\begin{array}{c}\Delta G^{\circ} \\
\left(\mathrm{kJ} \mathrm{mol}^{-1}\right)\end{array}$ \\
\hline Inosine & 15 & 1 & 1 & 8.77 & Inosine & -35.0 & 46.3 & -48.8 \\
\hline \multirow{2}{*}{ IMP } & \multirow{2}{*}{15} & 1 & 1 & 9.33 & (1) $\mathrm{L}^{-}+\mathrm{H}^{+} \rightleftharpoons \mathrm{LH}$ & & & \\
\hline & & 1 & 2 & 15.28 & & & & \\
\hline Inosine & 20 & 1 & 1 & 8.67 & & & & \\
\hline \multirow{2}{*}{ IMP } & \multirow{2}{*}{20} & 1 & 1 & 9.17 & & & & \\
\hline & & 1 & 2 & 15.17 & & & & \\
\hline Inosine & 25 & 1 & 1 & 8.55 & IMP & -33.0 & 64.6 & -52.2 \\
\hline \multirow{2}{*}{ IMP } & \multirow{2}{*}{25} & 1 & 1 & 9.09 & (2) $\mathrm{L}^{3-}+\mathrm{H}^{+} \rightleftharpoons \mathrm{LH}^{2-}$ & 0.32 & 114.6 & -33.8 \\
\hline & & 1 & 2 & 15.07 & (3) $\mathrm{LH}^{2-}+\mathrm{H}^{+} \rightleftharpoons \mathrm{LH}_{2}^{-}$ & & & \\
\hline Inosine & 30 & 1 & 1 & 8.44 & & & & \\
\hline \multirow{2}{*}{ IMP } & \multirow{2}{*}{30} & 1 & 1 & 8.95 & & & & \\
\hline & & 1 & 2 & 14.99 & & & & \\
\hline
\end{tabular}

${ }^{\mathrm{a}} p$ and $q$ are stoichiometric coefficients corresponding to ligand and $\mathrm{H}^{+}$, respectively; ${ }^{\mathrm{b}}$ data taken from reference [83]; $\mathrm{L}$ denotes inosine and inosine $5^{\prime}$. monophosphate.

The phosphate ion in IMP is more solvated than its protonated form. Consequently it contributes more to the endothermic process upon protonation and the net $\Delta H^{\circ}$ is only $0.32 \mathrm{~kJ} \mathrm{~mol}^{-1}$. Also, the phosphate ions form ordered hydrogen bonds with water molecules, which is confirmed by the large entropy change $\Delta S^{\circ}=114.6 \mathrm{JK}^{-1} \mathrm{~mol}^{-1}$. This contributes to a negative free energy change $\Delta G^{\circ}=$ $33.8 \mathrm{~kJ} \mathrm{~mol}^{-1}$. The positive entropies due to the release of ordered water molecules and the breaking of hydrogen bonds were found by Kramer-Schnabel and Linder [73] to give positive $\Delta H^{\circ}$, large $\Delta S^{\circ}$, and net negative $\Delta G^{\circ}$ for the protonation and complexation reactions of organic monophosphates and copper ions. The $\log _{10} K$ values decrease with increasing temperature revealing that its acidity increases with increasing temperature.

\section{Conclusions}

Great efforts should be made to collect data with as high quality as possible. This is often a time-consuming tough job but there are no short cuts in this respect. We would like to stress the importance of the following points.

(a) The amino acids have special importance among the other chemical molecules because they are the foundation stones of living organisms. The determination of the protonation constants is of great importance for the elucidation of numerous biological compounds.

(b) The knowledge of the protonation constants for these bioligands is a prerequisite to an understanding of their mechanism of action in both chemical and biological processes. Thus, it is hoped that these data will be a significant contribution to workers carrying out mechanistic studies in biological media. However, a fundamental understanding of the effects that structural variations have on the properties of the amino acid is essential in order to interpret and predict the properties of proteins correctly and also in order to explain the behaviors of enzymes in living organisms.

(c) In addition, the protonation constants of various amino acids investigated in this study not only are used for quantitative purposes but also can be used for the evaluation of the solvent effect and structural behavior of the amino acids in water containing media.

(d) Also, the present study supports the idea that the solvent effect on the protonation constants for the amino acids can be utilized to predict whether the zwitterion or the neutral form is the predominant species and how the zwitterionic to neutral form ratio changes with the concentration of organic component in water-organic solvent mixtures.

(e) The protonation constants of some dipeptides were determined in water and water-ethanol mixtures. Generally, it was observed that the $\log _{10} K_{1}$ values of dipeptides decrease and the $\log _{10} K_{2}$ values increase with the increase in the mole fraction of ethanol. The chemical and biological activity of these substances would be expected to vary with the degree of ionization. Therefore, a good knowledge of the protonation constants of dipeptides in nonaqueous media is of considerable interest.

(f) Additionally, the protonation constant of amino acid esters will be helpful in the determination of the microscopic equilibrium constants of the corresponding amino acids due to knowledge of the microscopic equilibrium constants of some compounds being necessary for the calculation of the concentration of each ionized species at any $\mathrm{pH}$, which is important for the complete understanding of the physicochemical behavior of such molecules. 
(g) The basicity of a compound is a result of various factors such as (i) the solvent effect (solvation power, the tendency of forming hydrogen bonds, selective solvation, dielectric constant, and the composition of the solution in the first solvation layer) in the case of mixed solvents and (ii) structural effects, electronic effects, and steric effects.

(h) Equilibrium constants are directly related to the solvent composition.

(i) The search for the equilibrium model must be unambiguous. The search for the speciation scheme as a service to the reader should be based on computerized methods and visualized in the form of diagrams.

(j) The discussed data in this study will make an important contribution to the literature.

$\begin{array}{ll}\text { Abbreviations } \\ \text { Ala: } & \text { Alanine } \\ \text { Cys: } & \text { Cysteine } \\ \text { D: } & \text { Dioxane } \\ \text { E: } & \text { Ethanol } \\ \text { DMSO: } & \text { Dimethyl sulfoxide } \\ \text { Gly: } & \text { Glycine } \\ \text { Gly-Gly: } & \text { Glycylglycine } \\ \text { GlyLeu: } & \text { Glycylleucine } \\ \text { GlyMet: } & \text { Glycylmethionine } \\ \text { GlyPhe: } & \text { Glycylphenylalanine } \\ \text { GlyThr: } & \text { Glycylthreonine } \\ \text { GlyVal: } & \text { Glycylvaline } \\ \text { His: } & \text { Histidine } \\ \text { IMP: } & \text { Inosine } 5^{\prime} \text {-monophosphate } \\ \text { Lys: } & \text { Lysine } \\ \text { Met: } & \text { Methionine } \\ \text { Trp: } & \text { Tryptophane } \\ \text { Tyr: } & \text { Tyrosine. }\end{array}$

\section{Conflict of Interests}

The authors declare that there is no conflict of interests regarding the publication of this paper.

\section{References}

[1] H. Kozłowski, W. Bal, M. Dyba, and T. Kowalik-Jankowska, "Specific structure-stability relations in metallopeptides," Coordination Chemistry Reviews, vol. 184, no. 1, pp. 319-346, 1999.

[2] H. Rossotti, The Study of Ionic Equilibria, Longman, London, UK, 1978.

[3] A. E. Martell and M. Calvin, Chemistry of the Metal Chelate Compounds, Prentice Hall, New York, NY, USA, 1952.

[4] F. C. Rossotti and H. Rossotti, The Determination of Stability Constant, McGraw-Hill, New York, NY, USA, 1961.

[5] R. G. Bates, Determination of $p H$, Theory and Practice, John Wiley \& Sons, New York, NY, USA, 2nd edition, 1975.

[6] H. Sigel and R. B. Martin, "Coordinating properties of the amide bond. Stability and structure of metal ion complexes of peptides and related ligands," Chemical Reviews, vol. 82, no. 4, pp. 385426, 1982.

[7] S. Fiol, I. Brandariz, and M. S. de Vicente, "The ionization constants of $\alpha$-alanine in $\mathrm{NaCl}$ at 25。. Effect of the ionic strength based on three models," Talanta, vol. 42, no. 6, pp. 797-801, 1995.

[8] J. I. Partanen, "Calculation of the first and second stoichiometric dissociation constants of glycine in aqueous sodium chloride solutions at $298.15 \mathrm{~K}$," Berichte der Bunsengesellschaft für physikalische Chemie, vol. 102, no. 6, pp. 855-865, 1998.

[9] A. A. El-Sherif, "Coordination properties of bidentate $(\mathrm{N}, \mathrm{O})$ and tridentate $(\mathrm{N}, \mathrm{O}, \mathrm{O})$ heterocyclic alcohols with dimethyltin (IV)," Journal of Coordination Chemistry, vol. 64, pp. 1240-1253, 2011.

[10] M. S. Aljahdali, A. T. Abdelkarim, A. A. El-Sherif, and M. M. Ahmed, "Synthesis, characterization, equilibrium studies, and biological activity of complexes involving copper(II), 2-aminomethylthiophenyl-4-bromosalicylaldehyde Schiff base, and selected amino acids," Journal of Coordination Chemistry, vol. 67, no. 5, pp. 870-890, 2014.

[11] A. A. El-Sherif, "Kinetics and mechanism for hydrolysis of $\alpha$-amino acid esters in mixed ligand complexes with $\mathrm{zn}(\mathrm{II})$ nitrilo-tris(methyl phosphonic acid)," Journal of Solution Chemistry, vol. 41, no. 2, pp. 249-260, 2012.

[12] A. A. El-Sherif, M. R. Shehata, M. M. Shoukry, and M. H. Barakat, "Thermodynamic investigation and mixed ligand complex formation of 1,4-Bis-(3-aminopropyl)-piperazine and biorelevant ligands," Bioinorganic Chemistry and Applications, vol. 2012, Article ID 984291, 10 pages, 2012.

[13] A. A. El-Sherif, M. M. Shoukry, W. M. Hosny, and M. G. AbdElmoghny, "Complex formation equilibria of unusual sevencoordinate $\mathrm{Fe}(\mathrm{EDTA})$ complexes with DNA constituents and related bio-relevant ligands," Journal of Solution Chemistry, vol. 41, no. 5, pp. 813-827, 2012.

[14] M. Aljahdali and A. A. El-Sherif, "Equilibrium studies of binary and mixed-ligand complexes of zinc(II) involving 2-(aminomethyl)-benzimidazole and some bio-relevant ligands," Journal of Solution Chemistry, vol. 41, no. 10, pp. 1759-1776, 2012.

[15] N. A. Al-Awadi, N. M. Shuaib, A. Abbas, A. A. El-Sherif, A. El-Dissouky, and E. Al-Saleh, "Synthesis, characterization, and biological activity of N1 -methyl-2-(1H-1,2,3-benzotriazol-1-yl)3-oxobutan-ethioamide complexes with some divalent metal (II) ions," Bioinorganic Chemistry and Applications, vol. 2008, Article ID 479897, 10 pages, 2008.

[16] R. J. Motekaitis and A. E. Martell, The Determination and Use of Stability Constants, VCH, New York, NY, USA, 1988.

[17] D. J. Legget, Ed., Computational Methods for the Determination of Formation Constants, Plenum Press, New York, NY, USA, 1985.

[18] M. Meloum, J. Havel, and E. Hgfeldt, Computation of Solution Equilibria, Ellis Horwood, Chichester, UK, 1994.

[19] J. Barbosa, D. Barrón, J. L. Beltrán, and V. Sanz-Nebot, “PKPOT, a program for the potentiometric study of ionic equilibria in aqueous and non-aqueous media," Analytica Chimica Acta, vol. 317, no. 1-3, pp. 75-81, 1995.

[20] A. E. Martell and R. J. Motekaitis, Determination and Use of Stability Constants, VCH Publishers, New York, NY, USA, 1992.

[21] R. J. Motekaitis and A. E. Martell, "A new program for rigorous calculation of equilibrium parameters of complex multi component systems," Canadian Journal of Chemistry, vol. 60, pp. 24032409, 1982. 
[22] A. Sabatini, A. Vacca, and P. Gans, "Miniquad: a general computer programme for the computation of formation constants from potentiometric data," Talanta, vol. 21, no. 1, pp. 53-77, 1974.

[23] P. Gans, A. Sabatini, and A. Vacca, "An improved computer program for the computation of formation constants from potentiometric data," Inorganica Chimica Acta, vol. 18, pp. 237-239, 1976.

[24] P. Gans, A. Sabatini, and A. Vacca, "SUPERQUAD: an improved general program for computation of formation constants from potentiometric data," Journal of the Chemical Society, Dalton Transactions, no. 6, pp. 1195-1200, 1985.

[25] A. Vacca and A. Sabatini, "MINIQUAD and MIQUV," in Computational Methods for the Determination of Formation Constants, D. J. Leggett, Ed., pp. 99-157, Plenum Press, New York, NY, USA, 1985.

[26] P. Gans, A. Sabatini, and A. Vacca, "Investigation of equilibria in solution. Determination of equilibrium constants with the HYPERQUAD suite of programs," Talanta, vol. 43, no. 10, pp. 1739-1753, 1996.

[27] J. J. Gooding, D. B. Hibbert, and W. Yang, "Electrochemical metal ion sensors. Exploiting amino acids and peptides as recognition elements," Sensors, vol. 1, no. 3, pp. 75-90, 2001.

[28] A. Gergely and E. Farkas, "Studies on transition-metalpeptide complexes," Journal of the Chemical Society, Dalton Transactions, pp. 381-395, 1982.

[29] M. S. Diaz-Cruz, J. M. Diaz-Cruz, J. Mendieta, R. Tauler, and M. Esteban, "Soft- and hard-modeling approaches for the determination of stability constants of metal-peptide systems by voltammetry," Analytical Biochemistry, vol. 279, no. 2, pp. 189201, 2000 .

[30] A. A. El-Sherif, M. M. Shoukry, R. M. El-Bahnasawy, and D. M. Ahmed, "Complex formation reactions of palladium(II)1,3-diaminopropane with various biologically relevant ligands. Kinetics of hydrolysis of glycine methyl ester through complex formation," Central European Journal of Chemistry, vol. 8, no. 4, pp. 919-927, 2010.

[31] B. B. Koleva, T. M. Kolev, and M. Spiteller, "Structural and spectroscopic analysis of hydrogensquarates of glycine-containing tripeptides," Biopolymers, vol. 83, no. 5, pp. 498-507, 2006.

[32] A. A. El-Sherif, M. M. Shoukry, and R. van Eldik, "Complexformation reactions and stability constants for mixed-ligand complexes of diaqua(2-picolylamine)palladium(II) with some bio-relevant ligands," Dalton Transactions, no. 7, pp. 1425-1432, 2003.

[33] G. Facchin, E. Kremer, E. J. Baran et al., "Structural characterization of a series of new Cu-dipeptide complexes in solid state and in solution," Polyhedron, vol. 25, no. 13, pp. 2597-2604, 2006.

[34] A. A. El-Sherif, "Mixed-ligand complexes of 2-(aminomethyl)benzimidazole palladium(II) with various biologically relevant ligands," Journal of Solution Chemistry, vol. 35, no. 9, pp. 1287-1301, 2006.

[35] B. B. Ivanova, T. Kolev, and S. Y. Zareva, "Solid-state IR-LD spectroscopic and theoretical analysis of glycine-containing peptides and their hydrochlorides," Biopolymers, vol. 82, no. 6, pp. 587-596, 2006.

[36] A. A. El-Sherif, "Synthesis, solution equilibria and antibacterial activity of $\mathrm{Co}$ (II) with 2-(aminomethyl)-benzimidazole and dicarboxylic acids," Journal of Solution Chemistry, vol. 39, no. 10, pp. 1562-1581, 2010.

[37] M. M. A. Mohamed and A. A. El-Sherif, "Complex formation equilibria between zinc(II), nitrilo-tris(methyl phosphonic acid) and some bio-relevant ligands. The kinetics and mechanism for zinc(II) ion promoted hydrolysis of glycine methyl ester," Journal of Solution Chemistry, vol. 39, no. 5, pp. 639-653, 2010.

[38] A. A. El-Sherif and M. M. Shoukry, "Coordination properties of tridentate $(\mathrm{N}, \mathrm{O}, \mathrm{O})$ heterocyclic alcohol (PDC) with $\mathrm{Cu}(\mathrm{II})$. Mixed ligand complex formation reactions of $\mathrm{Cu}$ (II) with PDC and some bio-relevant ligands," Spectrochimica Acta A, vol. 66, no. 3, pp. 691-700, 2007.

[39] A. A. El-Sherif and M. M. Shoukry, "Copper(II) complexes of imino-bis(methyl phosphonic acid) with some bio-relevant ligands: equilibrium studies and hydrolysis of glycine methyl ester through complex formation," Journal of Coordination Chemistry, vol. 58, no. 16, pp. 1401-1415, 2005.

[40] A. A. El-Sherif, "Stoichiometry book, the importance of quantity in biomedicine," in Coordination Chemistry of Palladium(II) Ternary Complexes with Relevant Biomolecules, pp. 79-120, InTech, Rijeka, Croatia, 2012.

[41] S. Rondinini, P. R. Mussini, and T. Mussini, "Reference value standards and primary standards for ph measurements," Journal of Pure and Applied Chemistry, vol. 59, no. 11, pp. 1549-1560, 1987.

[42] H. S. Harned and B. B. Owen, The Physical Chemistry of Electrolyte Solutions, Reinhold, New York, NY, USA, 3rd edition, 1958.

[43] M. Rosés, C. Ràfols, and E. Bosch, "Autoprotolysis in aqueous organic solvent mixtures," Analytical Chemistry, vol. 65, no. 17, pp. 2294-2299, 1993.

[44] G. Fonrodona, C. Ràfols, E. Bosch, and M. Rosés, "Autoprotolysis in aqueous organic solvent mixtures. Water/alcohol binary systems," Analytica Chimica Acta, vol. 335, no. 3, pp. 291-302, 1996.

[45] E. Kiliç and N. Aslan, "Determination of autoprotolysis constants of water-organic solvent mixtures by potentiometry," Microchimica Acta, vol. 151, no. 1-2, pp. 89-92, 2005.

[46] E. Canel, A. Gültepe, A. Doğan, and E. Kılıc, "The determination of protonation constants of some amino acids and their esters by potentiometry in different media," Journal of Solution Chemistry, vol. 35, no. 1, pp. 5-19, 2006.

[47] R. F. Jameson and M. F. Wilson, "Thermodynamics of the interactions of catechol with transition metals. Part I. Free energy, enthalpy, and entropy changes for the ionisation of catechol at $25^{\circ} \mathrm{C}$. Comparison of the temperature-coefficient method with direct calorimetry," Journal of the Chemical Society, Dalton Transactions, no. 23, pp. 2610-2614, 1972.

[48] A. Doğan, A. D. Özel, and E. Kiliç, “The protonation equilibria of selected glycine dipeptides in ethanol-water mixture: solvent composition effect," Amino Acids, vol. 36, no. 2, pp. 373-379, 2009.

[49] A. A. El-Sherif, "Mixed ligand complex formation reactions and equilibrium studies of $\mathrm{Cu}$ (II) with bidentate heterocyclic alcohol $(\mathrm{N}, \mathrm{O})$ and some bio-relevant ligands," Journal of Solution Chemistry, vol. 39, no. 1, pp. 131-150, 2010.

[50] A. Doğan, N. Aslan, E. Canel, and E. KIlIç, "Solvent effects on the protonation constants of some $\alpha$-amino acid esters in water1,4-dioxane-water mixtures," Journal of Solution Chemistry, vol. 39, no. 11, pp. 1589-1596, 2010.

[51] A. Golcu, M. Tumer, H. Demirelli, and R. A. Wheatley, "Cd(II) and $\mathrm{Cu}(\mathrm{II})$ complexes of polydentate Schiff base ligands: Synthesis, characterization, properties and biological activity," Inorganica Chimica Acta, vol. 358, no. 6, pp. 1785-1797, 2005. 
[52] D. L. Hughes, J. J. Bergan, and E. J. J. Grabowski, "Amino acid chemistry in dipolar aprotic solvents: dissociation constants and ambident reactivity," Journal of Organic Chemistry, vol. 51, no. 13, pp. 2579-2585, 1986.

[53] J. Crosby, R. Stone, and G. E. Lienhard, "Mechanisms of thiamine-catalyzed reactions. Decarboxylation of 2-(1-carboxy-1hydroxyethyl)-3,4-dimethylthiazolium chloride," Journal of the American Chemical Society, vol. 92, no. 9, pp. 2891-2900, 1970.

[54] M. Arroyo, R. Torres-Guzmán, I. de La Mata, M. P. Castillón, and C. Acebal, "Prediction of penicillin V acylase stability in water-organic co-solvent monophasic systems as a function of solvent composition," Enzyme and Microbial Technology, vol. 27, no. 1-2, pp. 122-126, 2000.

[55] A. Doğan, F. Köseoğlu, and E. Kılıç, "Studies on the macroscopic protonation constants of some $\alpha$-amino acids in ethanol-water mixtures," Analytical Biochemistry, vol. 309, no. 1, pp. 75-78, 2002.

[56] A. Doğan, F. Köseoğlu, and E. Kılıc, "Potentiometric studies on the protonation constants and solvation of some a-amino acid methyl- and ethyl esters in water-ethanol mixture," Indian Journal of Chemistry A, vol. 41, pp. 960-962, 2002.

[57] H. Sigel, "Ternary complexes in solution. XXIII. Influence of alkyl side chains on the stability of binary and ternary copper(II)-dipeptide complexes," Inorganic Chemistry, vol. 14, no. 7, pp. 1535-1540, 1975.

[58] M. Kilyén, P. Forgó, A. Lakatos et al., "Interaction of $\mathrm{Al}(\mathrm{III})$ with the peptides AspAsp and AspAspAsp," Journal of Inorganic Biochemistry, vol. 94, no. 3, pp. 207-213, 2003.

[59] A. N. Fonteh, R. J. Harrington, and M. G. Harrington, "Quantification of free amino acids and dipeptides using isotope dilution liquid chromatography and electrospray ionization tandem mass spectrometry," Amino Acids, vol. 32, no. 2, pp. 203212, 2007.

[60] M. M. Shoukry, E. M. Khairy, and A. A. El-Sherif, "Ternary complexes involving copper(II) and amino acids, peptides and DNA constituents. The kinetics of hydrolysis of $\alpha$-amino acid esters," Transition Metal Chemistry, vol. 27, no. 6, pp. 656-664, 2002.

[61] A. Q. Lyons and L. D. Pettit, "Formation constants of silver (I) complexes of some sulphur-containing dipeptides and valylvaline," Journal of the Chemical Society, Dalton Transactions, vol. 102, pp. 2305-2308, 1984.

[62] E. Canel, A. Gültepe, A. Doğan, and E. Kılıc, "The determination of protonation constants of some amino acids and their esters by potentiometry in different media," Journal of Solution Chemistry, vol. 35, no. 1, pp. 5-19, 2006.

[63] A. Doğan and E. Kılıc, "Potentiometric studies on the protonation constants and solvation of some $\alpha$-amino acid benzyland t-butyl-esters in water-ethanol mixtures," Turkish Journal of Chemistry, vol. 29, pp. 41-47, 2005.

[64] T. Gündüz, A. Doğan, E. Kılıc, and F. Köseoğlu, "Determination of stability constants of metal complexes with potentiometric pH titrations," Analytica Chimica Acta, vol. 282, pp. 489-495, 1993.

[65] F. Köseoǧlu, E. Kiliç, and D. Uysal, "Protonation constants of some substituted 2-hydroxy-1-naphthalideneanilines in dioxanwater mixtures," Talanta, vol. 42, no. 12, pp. 1875-1882, 1995.

[66] A. K. Chattopadhyay and S. C. Lahiri, "Studies on the solvation of amino acids in ethanol and water mixtures," Electrochimica Acta, vol. 27, no. 2, pp. 269-272, 1982.

[67] F. Köseoğlu, E. Kılıc, and A. Doğan, "Studies on the protonation constants and solvation of $\alpha$-amino acids in water- dioxane mixture," Analytical Biochemistry, vol. 277, no. 2, pp. 243-246, 2000.

[68] E. Kılıc, G. Gökçe, and E. Canel, "The protonation constants of some aliphatic alkylamines in water-ethanol mixtures," Turkish Journal of Chemistry, vol. 26, pp. 843-849, 2002.

[69] E. K1lıc, F. Köseoğlu, and Ö. Başgut, "Protonation constants of some pyridine derivatives in water-ethanol mixtures," Analytica Chimica Acta, vol. 294, no. 2, pp. 215-220, 1994.

[70] N. S. Isaacs, Physical Chem, Org., Longman, New York, NY, USA, 1986.

[71] R. G. Bates, "Solute-solvent interactions and acid-base dissociation in mixed solvent systems," Journal of Electroanalytical Chemistry, vol. 29, no. 1, pp. 1-19, 1971.

[72] N. Nishi, S. Takahashi, M. Matsumoto et al., "Hydrogen bonding cluster formation and hydrophobic solute association in aqueous solution of ethanol," Journal of Physical Chemistry $囚$, vol. 99, no. 1, pp. 462-468, 1995.

[73] U. U. Kramer-Schnabel and P. W. Linder, "Substituent effects in the protonation and complexation with copper(II) ions of organic monophosphate esters. A potentiometric and calorimetric study," Inorganic Chemistry, vol. 30, no. 6, pp. 1248-1254, 1991.

[74] D. C. Rees, "Experimental evaluation of the effective dielectric constant of proteins., Journal of Molecular Biology, vol. 141, no. 3, pp. 323-326, 1980.

[75] N. K. Rogers, G. R. Moore, and M. J. E. Sternberg, "Electrostatic interactions in globular proteins: Calculation of the $\mathrm{pH}$ dependence of the redox potential of cytochrome c551," Journal of Molecular Biology, vol. 182, no. 4, pp. 613-616, 1985.

[76] G. Akerlof and O. A. Short, "The dielectric constant of waterdioxane mixtures between 0 and 80 degrees-correction," Journal of the American Chemical Society, vol. 75, no. 24, pp. 6357-6357, 1953.

[77] M. N. Roy, B. Sinha, R. Dey, and A. Sinha, "Solute-solvent and solute-solute interactions of resorcinol in mixed 1,4-dioxanewater systems at different temperatures," International Journal of Thermophysics, vol. 26, no. 5, pp. 1549-1563, 2005.

[78] M. Bešter-Rogač, R. Neueder, and J. Barthel, "Conductivity of sodium chloride in water $+1,4$-dioxane mixtures at temperature from 5 to 35०C I. Dilute solution," Journal of Solution Chemistry, vol. 28, no. 9, pp. 1071-1086, 1999.

[79] R. Tribolet, R. Malini-Balakrishnan, and H. Sigel, "Influence of decreasing solvent polarity (dioxane-water mixtures) on the stability and structure of binary and ternary complexes of adenosine 5/-triphosphate and uridine 5/-triphosphate," Journal of the Chemical Society, Dalton Transactions, no. 11, pp. 2291-2303, 1985.

[80] C. C. Panichajakul and E. M. Woolley, "Potentiometric method for determination of acid ionization constants in aqueous organic mixtures," Analytical Chemistry, vol. 47, no. 11, pp. 1860$1863,1975$.

[81] H. Irving and H. Rosotti, "The theoretical basis of "sensitivity tests" and their application to some potential organic reagents for metals," Analyst, vol. 80, no. 949, pp. 245-260, 1955.

[82] H. Irving and H. Rosotti, "Some relationships among the stabilities of metal complexes," Acta Chemica Scandinavica, vol. 10, pp. 72-93, 1956.

[83] M. S. K. Niazi and J. Mollin, "Dissociation constants of some amino acid and pyridinecarboxylic acids in ethanol- $\mathrm{H}_{2} \mathrm{O}$ mixtures," Bulletin of the Chemical Society of Japan, vol. 60, no. 7, pp. 2605-2610, 1987. 
[84] R. A. Robinson and R. H. Stokes, Electrolyte Solutions, Academic Press, New York, NY, USA, 1959.

[85] J. Barbosa, D. Barrón, J. L. Beltrán, and S. Butí, "On the role of solvent in acid-base equilibria of diuretics in acetonitrile-water mixed solvents," Talanta, vol. 45, no. 5, pp. 817-827, 1998.

[86] T. Takamuku, A. Yamaguchi, M. Tabata et al., "Structure and dynamics of 1,4-dioxane-water binary solutions studied by X-ray diffraction, mass spectrometry, and NMR relaxation," Journal of Molecular Liquids, vol. 83, no. 1-3, pp. 163-177, 1999.

[87] H. A. Azab, A. M. El-Nady, and M. S. Saleh, "Potentiometric determination of the second stage dissociation constant of $\mathrm{N}$ [Tris-(hydroxymethyl)-methyl]-2-aminoethane-sulphonic acid (TES) in different solvent mixtures," Monatshefte für Chemie Chemical Monthly, vol. 125, no. 3, pp. 233-240, 1994.

[88] M. M. A. Mohamed, M. R. Shehata, and M. M. Shoukry, "Trimethyltin(IV) complexes with some selected DNA constituents," Journal of Coordination Chemistry, vol. 53, no. 2, pp. 125-142, 2001.

[89] H. Köksal, M. Dolaz, M. Tümer, and S. Serin, "Copper(II), cobalt(III), nickel(II), palladium(II), and zinc(II) complexes of the schiff base ligands derived from 2,6-diacetylpyridine and phthaldialdehyde," Synthesis and Reactivity in Inorganic and Metal-Organic Chemistry, vol. 31, no. 7, pp. 1141-1162, 2001.

[90] D. Martin and H. G. Hauthal, Dimethyl Sulphoxide, Van Nostrand Reinhold, Workingham, UK, 1975.

[91] R. Hernández-Molina, A. Mederos, P. Gili et al., "Coordinating ability in DMSO-water 80:20 wt./wt. of the Schiff base N,N $/$ 3,4-toluenebis(salicylideneimine) with divalent cations: crystal structure of the nickel(II) complex," Inorganica Chimica Acta, vol. 256, no. 2, pp. 319-325, 1997.

[92] A. A. El-Sherif, M. M. Shoukry, and M. M. A. Abd-Elgawad, "Protonation equilibria of some selected $\alpha$-amino acids in DMSO-water mixture and their $\mathrm{Cu}(\mathrm{II})$-complexes," Journal of Solution Chemistry, vol. 42, no. 2, pp. 412-427, 2013.

[93] A. Doğan, F. Köseoğlu, E. Kılıc et al., “The stability constants of copper (II) complexes with some $\alpha$-amino acids in waterdioxane mixtures," Analytical Biochemistry, vol. 295, pp. 237239, 2001. 

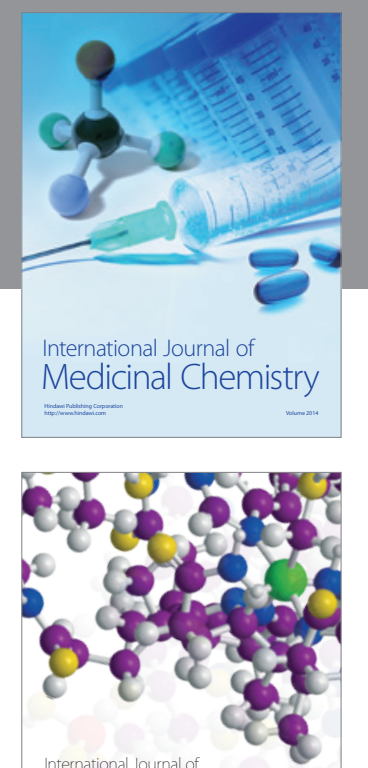

\section{Carbohydrate} Chemistry

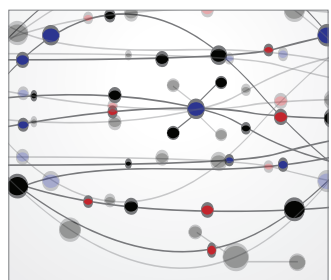

The Scientific World Journal
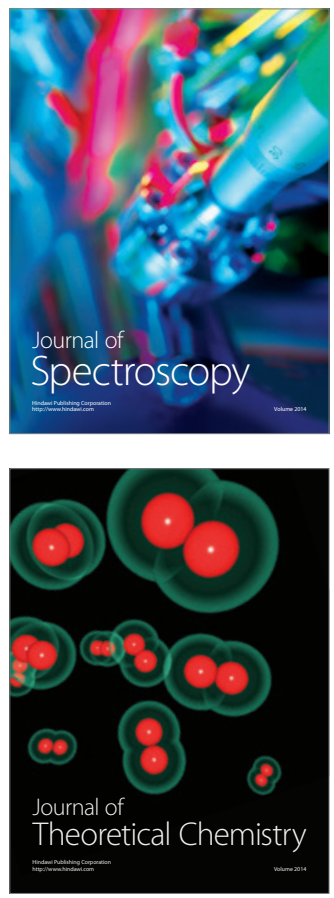
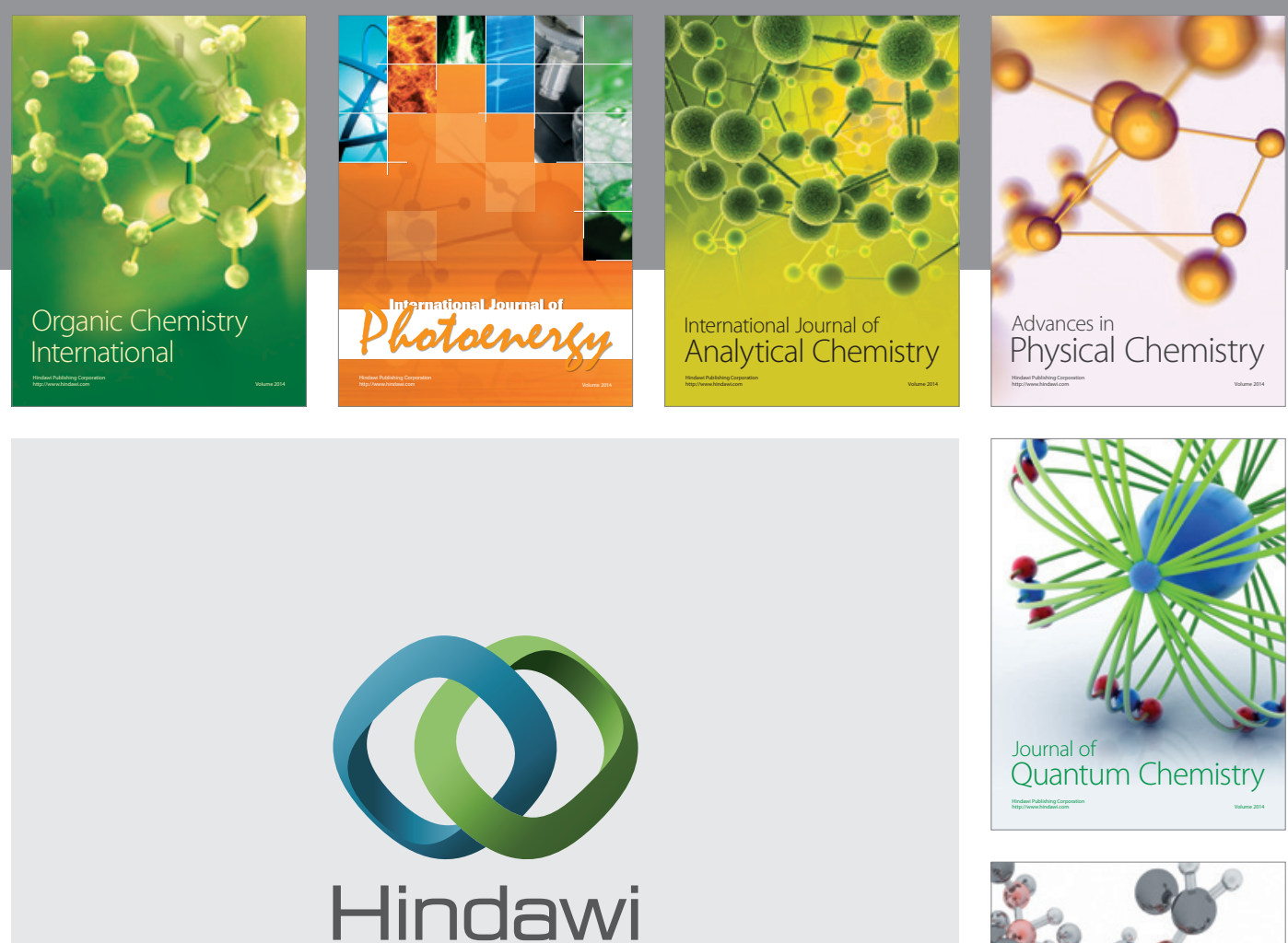

Submit your manuscripts at

http://www.hindawi.com

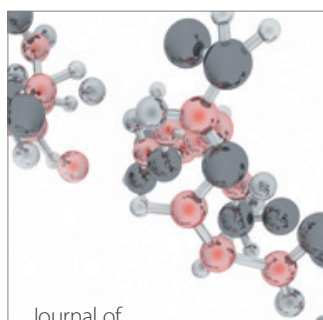

Analytical Methods

in Chemistry

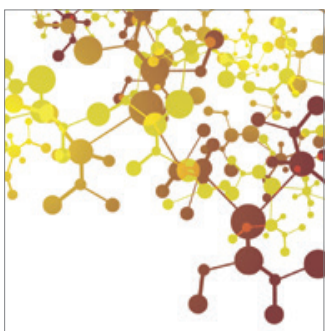

Journal of

Applied Chemistry

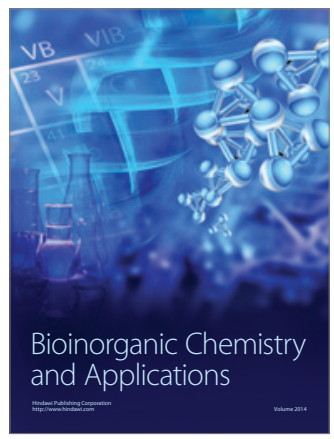

Inorganic Chemistry
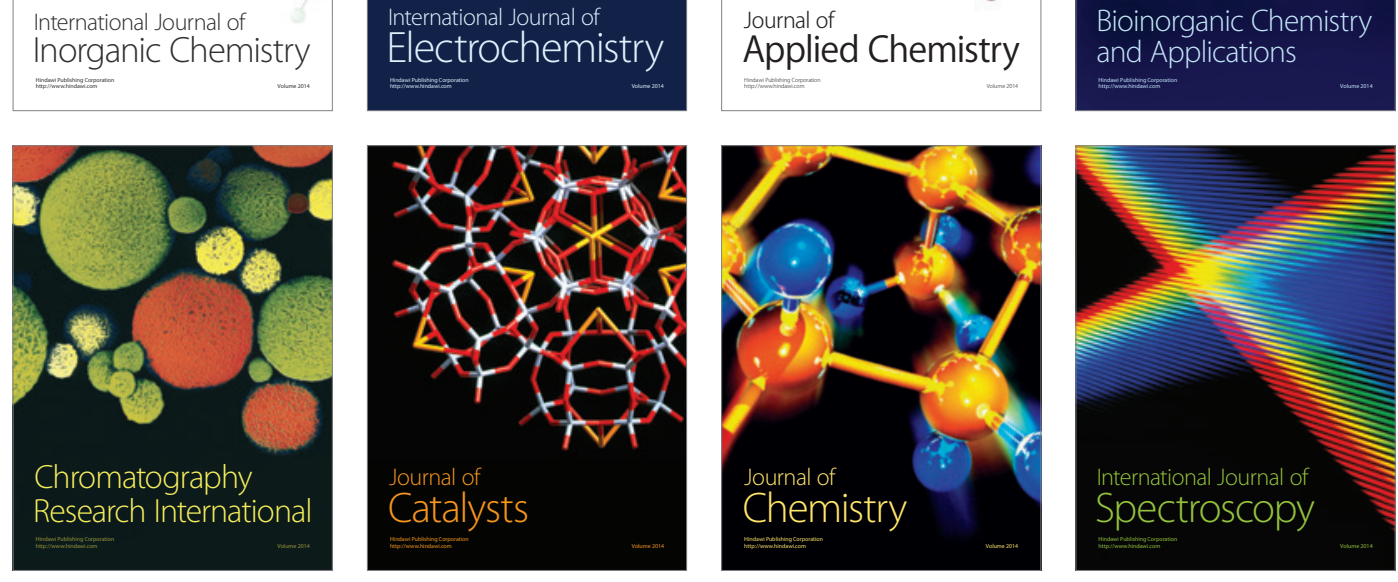